\title{
Tipos de redes personales de los inmigrantes y adaptación psicológica
}

\author{
I sidro Maya J ariego \\ Departamento de Psicología Social \\ Universidad de Sevilla
}

\begin{abstract}
Elaboramos una tipología de redes de apoyo en un colectivo de inmigrantes marroquíes $(n=81)$, filipinos $(n=69)$ y senegaleses $(n=23)$ residentes en Marbella, aplicando la entrevista Mannheim de apoyo social (MISS) (Veiel, 1990, 1993). Primero realizamos tres análisis de conglomerados exploratorios utilizando como variables-criterio indicadores de (1) composición familiar y étnica, (2) funciones de apoyo, y (3) tamaño y estructura de la red. Los análisis de chi-cuadrado entre las tres clasificaciones revelaron la solución de cinco clusters como la más apropiada. Para elaborar una tipología global con cinco categorías, seleccionamos siete indicadores de la red de apoyo, tomando en consideración para elegir cada variable: la diferenciación entre clusters, la saturación en una solución factorial y la matriz de correlaciones. Las variables-criterio seleccionadas fueron: disponibilidad de apoyo cotidiano psicológico, disponibilidad de apoyo instrumental en situaciones de crisis, número de compatriotas en la red de apoyo, número de españoles en la red de apoyo, número de familiares en la red de apoyo, número de no-familiares en la red de apoyo, y multiplicidad media de los vínculos. Los cinco clusters resultantes fueron (1) redes pequeñas de amigos y familiares compatriotas, (2) redes étnicas con predominio de vínculos especializados, (3) redes sinérgicas con predominio de amigos compatriotas, (4) redes étnicas de reagrupamiento familiar, y (5) redes de reagrupamiento familiar integradas en la comunidad receptora. Los tres colectivos estudiados tienen un perfil claramente diferenciado en sus redes personales: el $60 \%$ de los marroquíes se ubica en la categoría de redes más pequeñas, y el $60 \%$ de los senegaleses pertenece a grupos de compatriotas polivalentes. Por último, la tipología distingue significativamente los niveles de bienestar psicológico y el grado de utilización de servicios sociales. Los inmigrantes con redes pequeñas obtienen las puntuaciones más altas en la escala de depresión del Center for Epidemiological Studies (CES-D) (Radloff, 1977), mientras que las redes de reagrupamiento (étnicas o mixtas) se asocian significativamente a una mayor utilización de servicios sociales.
\end{abstract}

\section{A. Introducción}

La investigación previa ha examinado la influencia de múltiples dimensiones de las redes de apoyo social en la adaptación psicológica de los inmigrantes. Por ejemplo, se tiene constancia de que entre los elementos que atenúan o previenen la depresión en ése colectivo se cuentan tener una red amplia, estar casado, disponer de apoyo confidente y estar satisfecho con las relaciones interpersonales (véase por ejemplo: Maya, 1999). Este tipo de variables también tiene un efecto positivo en la percepción de salud física y autonomía funcional (Angel y Angel, 1992; Bialik-Gilad, 1988; Sasao y Chun, 1994), la satisfacción con la vida (Angel y Angel, 1992; Hernández y Gilbert, 1987; Lai y McDonald, 1995), el bienestar general percibido (Sasao y Chun, 1994), el estado de ánimo (Bialik-Gilad, 1988), el afecto positivo hacia el trabajo y la familia (Hernández y Gilbert, 1987), la satisfacción con la migración (Ying, 1996), la confianza en las relaciones con el entorno (Tyler, Tyler, Tommasello y Zhang, 1992), etcétera.

En segundo lugar, se ha documentado la influencia de las redes de apoyo en indicadores objetivos de adaptación. En concreto, existen evidencias al respecto de la inserción laboral (Greenwell, Valdez y DaVanzo, 1997; Schwarzer y Hahn, 1995), la rentabilidad de los pequeños negocios de inmigrantes (Bates, 1994), la intención 
de desplazarse a otro destino laboral (Sánchez y Viscarra, 1995); las calificaciones en inglés y matemáticas (Fuligni, 1997), el ajuste académico autoinformado (J ou y Fukada, 1996; Zea, Jarama y Bianchi, 1995); la segregación de roles en la toma de decisiones (Dasgupta, 1992; Schönpflug, Silbereisen y Schulz, 1990), la calidad de las relaciones padres-hijos (Dihn, Sarason y Sarason, 1994), los casos de maltrato infantil (Ima y Hohm, 1991), la percepción del rol de madre (Zambrana, SilvaPalacios y Powell, 1992), y el peso del hijo al nacer (Sherraden y Barrera, 1996), entre otros.

Sin embargo, la literatura ha prestado menos atención al papel de los tipos de redes de apoyo, pese a que constituyen una manera parsimoniosa y eficiente de analizar el proceso de adaptación al nuevo entorno (Maya, 1999). Las tipologías elaboradas con otras poblaciones muestran que sirven para predecir resultados de interés, como el bienestar subjetivo o la utilización de servicios sociales y de salud (Fudge, Neufeld y Harrison, 1997; Litwin, 1995, 1997a, 1997b; Wenger, 1991). En un trabajo previo, clasificamos las redes personales de inmigrantes africanos en cuatro categorías: (1) redes pequeñas con predominio de amigos compatriotas, (2) redes insuficientes con predominio de amigos compatriotas, (3) redes mixtas de tamaño medio centradas en los amigos, y (4) redes de tamaño medio centradas en la familia. Con dicha tipología distinguimos significativamente los niveles de bienestar psicológico, el estilo de uso de prestaciones sociales, así como otras características psicológicas, sociales y demográficas.

Siguiendo con esa línea de indagación, en esta comunicación pretendemos (1) clasificar las redes personales de un colectivo de inmigrantes africanos y asiáticos, y (2) examinar la asociación del tipo de red con indicadores de depresión y accesibilidad a servicios sociales.

\section{B. Metodología}

\section{Descripción de los tres colectivos estudiados}

Efectuamos un muestreo intencional para poner en perspectiva las condiciones de adaptación de dos grupos africanos y uno de origen asiático. Entrevistamos a un total de 173 inmigrantes residentes en Marbella. De éstos, 81 eran marroquíes, 69 filipinos y 23 senegaleses. El tamaño de estos tres colectivos en la provincia de Málaga es muy desigual: los oriundos de Marruecos constituyen una comunidad unas 4 veces más grande que la filipina, mientras que ésta última puede ser prácticamente 10 veces mayor que la senegalesa.

Como promedio, los encuestados tienen en torno a 37 años, y llevan residiendo en España algo más de 9 años. Se trata de una migración madura y estable, pues son pocos los casos en que no se cuenta con otros familiares que hayan emigrado (14.5\%), a la vez que la mayoría de ellos no se ha movido de la provincia de Málaga $(71.5 \%)$, ni tiene intención de volver a su país $(76.1 \%)$. Además, sólo un 9.4\% estaba en situación irregular en el momento de la entrevista, mientra que el resto afirmaba disponer de permiso de residencia $(41.2 \%)$, permiso de trabajo $(26.5 \%)$, o incluso permiso comunitario $(22.1 \%)$.

En cualquier caso, los senegaleses tienen algunos rasgos peculiares en relación a este perfil, ya que expresan con más frecuencia intención de retorno al país de origen $(47.8 \%)$, y muestran mayor movilidad geográfica desde que están en España $(43.5 \%)$. Además, su edad está al menos 5 puntos por encima del total de la muestra - tienen una media de 42 años-, y es más frecuente que hayan sido pioneros en su familia $(40.9 \%)$, o que hayan entrado clandestinamente en España $(21.7 \%)$. 
Las ocupaciones más habituales de estos tres grupos de extranjeros son el servicio doméstico, la venta ambulante y la hostelería. El grupo más numeroso entre marroquíes y filipinos lo forman las empleadas del hogar, aunque también hay un porcentaje significativo que se dedica a la hostelería. Por su parte, prácticamente todos los senegaleses trabajan en la venta ambulante. Entre los marroquíes hay situaciones laborales más diversas, pues encontramos quienes se dedican a la construcción, la jardinería, las reparaciones, etcétera.

Esta lógica de los segmentos laborales por nacionalidad también se refleja en el género, dado que los senegaleses constituyen el único colectivo de la muestra predominantemente masculino (95.7\%): frente a ello, la marroquí es una nacionalidad equilibrada en cuanto al género, mientras que en la comunidad filipina predominan las mujeres.

Pese a la convergencia en muchas de las variables demográficas y relativas al proyecto migratorio, la comunidad filipina muestra un mayor nivel socioeconómico. Tienen un nivel educativo superior, pues casi todos los entrevistados han cursado al menos la enseñanza secundaria $(95.6 \%)$, y dentro de éstos hay un grupo significativo con estudios universitarios $(42.7 \%)$. Unido a ello, más del $44 \%$ supera las 91.000 pesetas mensuales, mientras que entre los marroquíes se cuenta sólo un $20 \%$ en ese intervalo, y entre los senegaleses ninguno declara alcanzar dicho límite.

\section{Procedimiento}

Las entrevistas fueron realizadas en pareja, por un encuestador español y un mediador de la misma nacionalidad del entrevistado. El papel del mediador consistió en facilitar los contactos con la comunidad en cuestión, y hacer de intérprete en aquellos casos en los que fue necesario. Los mediadores contaban con experiencia previa en servicios sociales o en la aplicación de encuestas. La entrevista se aplicó en el idioma elegido por el entrevistado, registrando dicho extremo como indicador de aculturación.

Para reclutar a los encuestados se siguió el procedimiento de selección en cadena; y con una guía de investigación (Taft, 1986), controlamos la heterogeneidad de la muestra en tiempo de estancia, dominio del idioma, estrategia de aculturación, y barrio de residencia.

\section{Instrumentos}

La entrevista consistió en la aplicación de un cuestionario y varias escalas de evaluación de variables psicológicas. En el cuestionario se hicieron preguntas sobre el proyecto migratorio, la situación laboral, los problemas percibidos y la utilización de servicios sociales. Para valorar el conocimiento que los inmigrantes tienen sobre servicios sociales, se les pidió que señalaran qué organizaciones y prestaciones conocen y utilizan, así como el grado de satisfacción con las mismas. Las prestaciones del Ayuntamiento se analizaron en el contexto de otros servicios y entidades. La pertinencia de las preguntas se validó en una reunión previa con representantes de sindicatos, organizaciones no gubernamentales y profesionales de servicios sociales. Como índices agregados nos servimos del número de servicios conocidos y utilizados desde que el inmigrante reside en España. El número de servicios conocidos osciló entre 0 y 12, con una media de 4.46 y una desviación tipo de 2.59. Por su parte, el número de servicios utilizados osciló entre 0 y 6 , con una media de 1.24 y una desviación tipo de 1.35 . El $6.4 \%$ de la muestra no 
reconoce ninguno de los servicios evaluados, mientras que un $37.6 \%$ informa de no haber recurrido a prestaciones sociales profesionales desde que está en España.

Para evaluar las redes de apoyo de los inmigrantes se utilizó la Entrevista de Apoyo Social de Manheimm (Veiel, 1990, 1993), en la que se valora el apoyo instrumental y afectivo disponible, distinguiendo situaciones cotidianas de situaciones de crisis. Además se informa de la adecuación de la red de apoyo y la frecuencia de contactos, entre otros aspectos.

También se utilizó la escala de Depresión del Centro de Estudios Epidemiológicos (CES-D), instrumento de auto-informe de 20 ítems relativos a la ocurrencia de síntomas depresivos (Radloff, 1977). Esta escala ha sido utilizada tanto en población general como inmigrante de distinto origen étnico $\mathrm{y} / \mathrm{o}$ cultural, obteniendo en todos los casos adecuados indicadores de validez y fiabilidad (Vega, Kolody y Valle, 1998; Frank y Faux, 1990; Peterson, Folkman y Bakeman, 1996; Jon, 1998; Hovey, 1999). Recientemente la escala ha sido empleada en España en distintos contextos. Soler et al. (1997) realizan su validación en una población española de pacientes con trastornos afectivos, y en el ámbito comunitario Ferrer y Rodríguez (1999) la utilizan en un estudio descriptivo en atención primaria. De acuerdo con los estudios de validación en encuestas comunitarias (Eaton y Kessler, 1981), el punto de corte para reconocer un caso de depresión es 16, y en los estudios epidemiológicos se ha observado que aproximadamente el $18 \%$ o $20 \%$ de la población supera dicho umbral. El coeficiente de fiabilidad para el total de la muestra fue .83 , y en los tres grupos étnicos se obtuvieron índices similares (.82 en marroquíes, .83 en senegaleses y .81 en filipinos).

\section{Análisis de datos Análisis exploratorio de conglomerados}

La elaboración de conglomerados conlleva experimentar con una serie de soluciones de clusters, hasta que las agrupaciones reflejen presupuestos teóricos relevantes. La clasificación en parte es construida y en parte "se descubre". En este caso, realizamos tres tipologías exploratorias, contando para ello, respectivamente, con variables criterio de (1) composición, (2) funciones y (3) estructura de la red personal. Con cada una de ellas derivamos 4 clusters, de forma que obtuviéramos una distribución equilibrada de sujetos entre categorías. Se estableció un máximo de 10 iteraciones con un criterio de convergencia de 0.02. Para describir a los individuos que pertenecen a cada categoría, cruzamos (con tablas de contingencia chi-cuadrado), los tipos de redes con las variables demográficas, socio-económicas y de proyecto migratorio recogidas en nuestro estudio. A continuación, aplicamos un análisis oneway de la varianza, para determinar las diferencias de bienestar psicológico y utilización de servicios en función del tipo de red personal.

\section{Tipología según la composición familiar y étnica}

En primer lugar clasificamos a los encuestados utilizando cuatro indicadores de composición de la red: número de compatriotas proveedores de apoyo, número de españoles, número de familiares y número de no familiares. Los resultados del análisis de conglomerados, resumidos en la Tabla 1.1, reflejan el claro predominio de contactos de apoyo con miembros del propio grupo étnico. Prácticamente el $90 \%$ de los inmigrantes entrevistados tiene menos de un $13 \%$ de españoles en su red personal. Por otro lado, los cuatro clusters resultantes difieren claramente en el tamaño medio de la red de apoyo, de forma que la disponibilidad total de ayuda parece funcionar como una variable latente que distingue entre categorías. A continuación describimos las características de los cuatro conglomerados. 
Redes étnicas de familiares y amigos (Tipo 2). Casi la mitad del colectivo cuenta sólo con cinco proveedores de ayuda como promedio. Es la red de apoyo más pequeña de entre las cuatro identificadas. Se trata de un núcleo de compatriotas formado por parientes y amigos a partes iguales.

Gráfico 1. Tipos de redes personales según composición

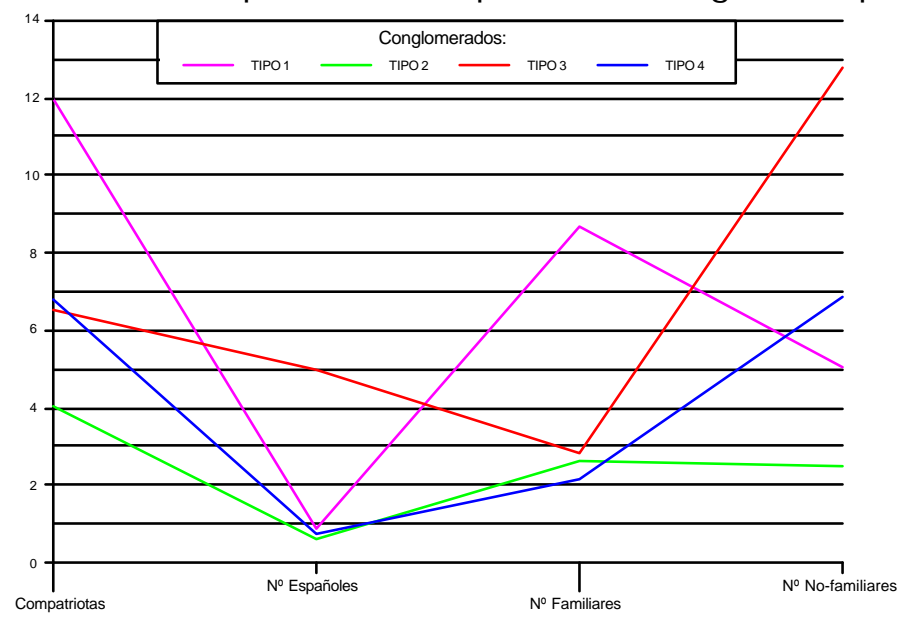

Redes étnicas con predominio de amigos (Tipo 4). El segundo tipo de red más frecuente $(30 \%)$ difiere del anterior por una mayor disponibilidad de vínculos no familiares: es una red más grande (con unos ocho lazos personales), gracias a que disponen de 2.5 veces más amigos que la anterior.

Redes étnicas con predominio de familiares (Tipo 1). Un pequeño porcentaje de entrevistados destaca por tener el triple (o más) familiares que el resto de categorías. Ocho de los trece individuos que como promedio conforman este tipo de red son parientes de la persona focal. Es, comparativamente, la red personal de mayor tamaño.

Redes mixtas con predominio de amigos (Tipo 3). La última agrupación es la única con una composición equilibrada entre miembros del propio grupo étnico y miembros de la sociedad de acogida. En torno a un $10 \%$ de inmigrantes cuenta con 5 españoles como promedio en su red personal. Se trata, como en el caso anterior, de una malla social particularmente extensa.

De acuerdo con los análisis bivariados (Tablas 1.2 a 1.5), la composición de la red personal se relaciona significativamente con la nacionalidad del inmigrante, el tiempo de estancia, la edad, la ocupación laboral y el número de familiares en España. Por el contrario, no guarda relación con el género, el estado civil, los años de escolarización, el nivel de ingresos, el proyecto migratorio ni la movilidad geográfica.

Gráfico 2. Porcentaje con cada tipo de red de apoyo 


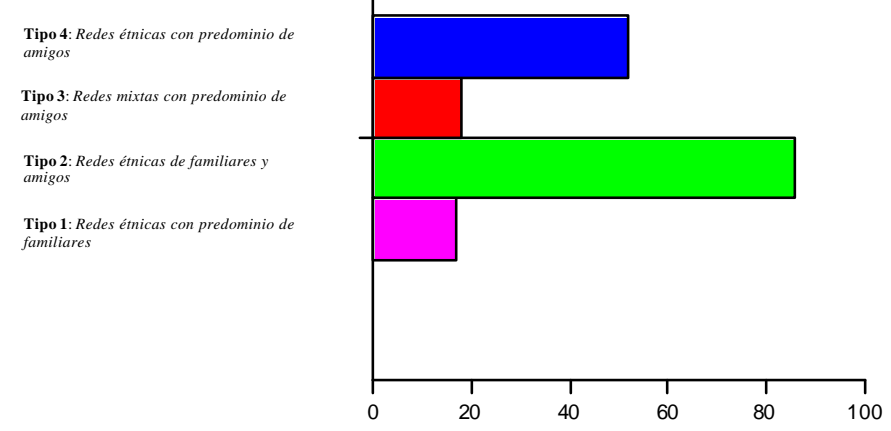

En las redes étnicas de familiares y amigos (Tipo 2) están significativamente representados los marroquíes, mientras que ocurre al contrario con los senegaleses. Es poco probable que se dediquen a la venta ambulante, y comparativamente es más habitual que estén desempleados. Se trata del grupo con menos tiempo de estancia en España. Es más común que tengan permiso de residencia o tarjeta de estudiante, y menos el permiso de trabajo.

Al contrario que la anterior, las redes étnicas con predominio de amigos (Tipo 4), es más frecuente en los senegaleses y menos en los marroquíes. Es el grupo con la media de edad más elevada, por encima de los 40 años y tienden a ocupar los intervalos inferiores de ingresos económicos. Cuentan con el menor número de familiares en España y es frecuente que se dediquen a la venta ambulante.

Los encuestados con redes étnicas con predominio de familiares (Tipo 1) conforman el grupo que lleva más tiempo residiendo en España y, en consonancia con ello, disponen de más familiares asentados en el contexto receptor. Todos los asignados a este grupo declaran su intención de permanecer en España, conformando el colectivo con un proyecto más estable.

El conglomerado de redes mixtas con predominio de amigos (Tipo 3) es el que cuenta comparativamente con mayor proporción de hombres y de solteros. Como promedio, son entre 5 y 11 años más jóvenes que el resto de entrevistados. Tienden a ocupar los intervalos superiores de ingresos mensuales y es más probable que cuenten con vivienda en propiedad. Ninguno de los pertenecientes a este subgrupo se dedican al servicio doméstico o están desempleados, mientras que hay una alta proporción de vendedores ambulantes. Los senegaleses están significativamente representados en este grupo.

Gráfico 3. Depresión y accesibilidad a servicios sociales según tipo de redes (composición) 


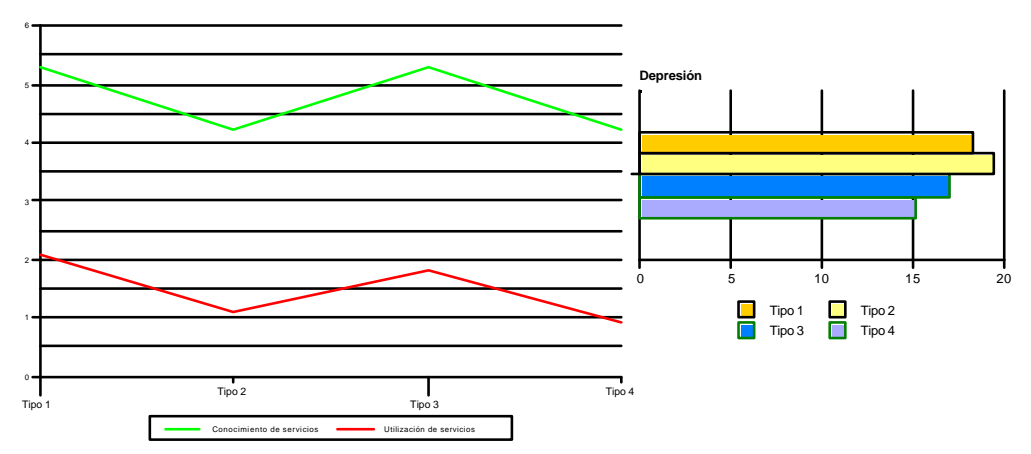

Las cinco categorías no discrepan en las dimensiones comportamentales ni valorativas del apoyo social. Los individuos de uno y otro cluster tampoco difieren de modo significativo en los indicadores de bienestar psicológico. Sin embargo, sí hay diferencias en el número de servicios sociales utilizados desde que están en España: los inmigrantes con redes étnicas en las que predominan familiares son los que han hecho uso de más prestaciones.

\section{Tipología según las funciones de apoyo}

En segundo lugar, elaboramos agrupaciones conforme a la disponibilidad de apoyo en cuatro áreas diferentes: ayuda psicológica en situaciones cotidianas, ayuda instrumental en situaciones cotidianas, ayuda psicológica en situaciones de crisis y ayuda instrumental en situaciones de crisis. Como era de esperar, en líneas generales los inmigrantes disponen potencialmente de más apoyo psicológico que instrumental, y cuentan con más proveedores para las demandas del día a día que en circunstancias de crisis (Tabla 2.1). Como en la primera tipología, también en este caso el tamaño de la red de apoyo funciona como una variable latente que distingue entre categorías. Sin embargo, para denominar los cuatro clusters utilizamos las discrepancias en las variables criterio. A continuación describimos las características de los cuatro conglomerados resultantes.

Gráfico 4. Tipos de redes personales según funciones 


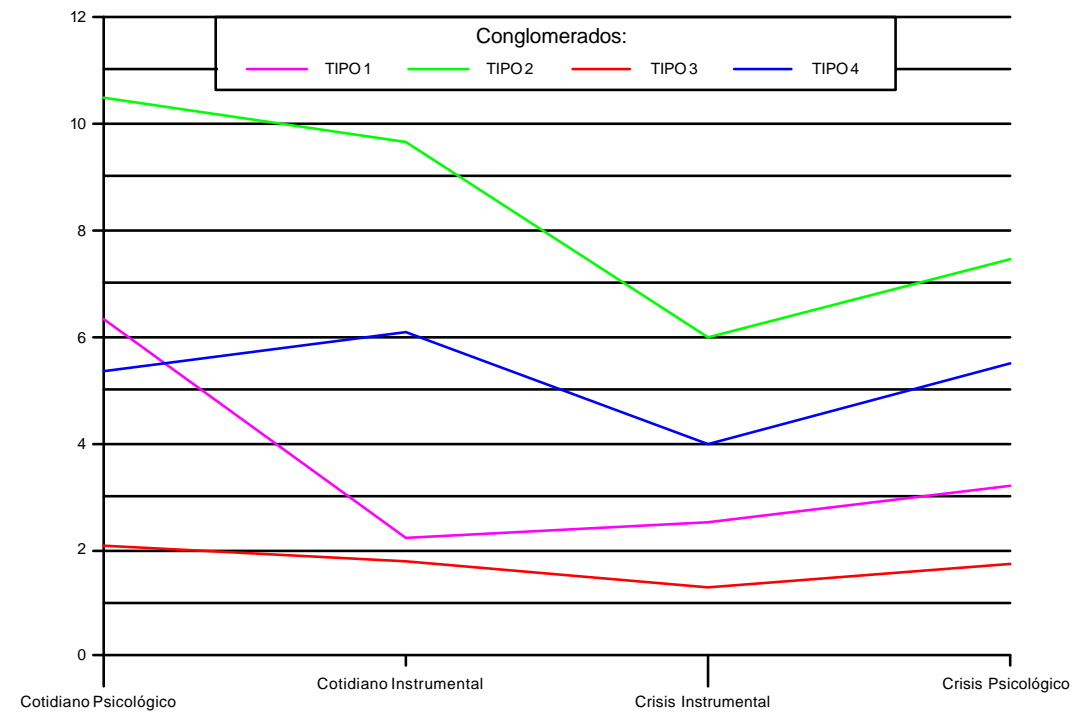

Redes poco diferenciadas (Tipo 3). Más de la mitad del grupo estudiado tiene en torno a cinco individuos en su red, y apenas cuenta con dos personas en cada área de necesidad. El menor tamaño de la red de apoyo parece guardar relación con el hecho de que no haya diferencias significativas en la disponibilidad de ayuda para cada función: en cada caso se recurre a los escasos vínculos disponibles.

Redes con predominio de funciones psicológicas (Tipo 1). Destaca por ser la red personal en la que se observa mayor distancia entre la disponibilidad de ayuda psicológica e instrumental. Aunque los inmigrantes incluídos en esta categoría cuentan con unos nueve proveedores (bastante por encima del tamaño modal de las redes de apoyo), la cantidad de lazos personales se aprovecha mejor para cubrir necesidades psicológicas que instrumentales. Esta estructura reticular la ha desarrollado en torno a un quinto de los encuestados.

Redes funcionalmente compensadas (Tipo 4). Aunque el tamaño de esta red personal es muy parecido al del tipo anterior (unos ocho vínculos), son bien diferentes en cuanto a los recursos que suelen proporcionar: las áreas de ayuda psicológica y cotidiana están igualmente atendidas; pero, por comparación, las áreas nstrumental y de crisis parecen particularmente bien cubiertas en este tipo de red. También en este caso estamos hablando de un quinto de los entrevistados.

Redes con predominio de apoyo cotidiano (Tipo 2). Esta agrupación recoge a aquellos individuos que han sido capaces de conformar una red amplia de en torno a catorce contactos personales. Goza de los niveles más elevados de disponibilidad en cada función. Todas las áreas cuentan con 5 o más vínculos, si bien sobresale la diferencia entre las funciones cotidianas y las de crisis, a favor de las primeras. En este pequeño porcentaje de la muestra (5\%) se mantiene la lógica de mayor disponibilidad en las funciones psicológicas que en las instrumentales, y en las cotidianas que en las de crisis.

Gráfico 5. Porcentaje con cada tipo de red de apoyo 


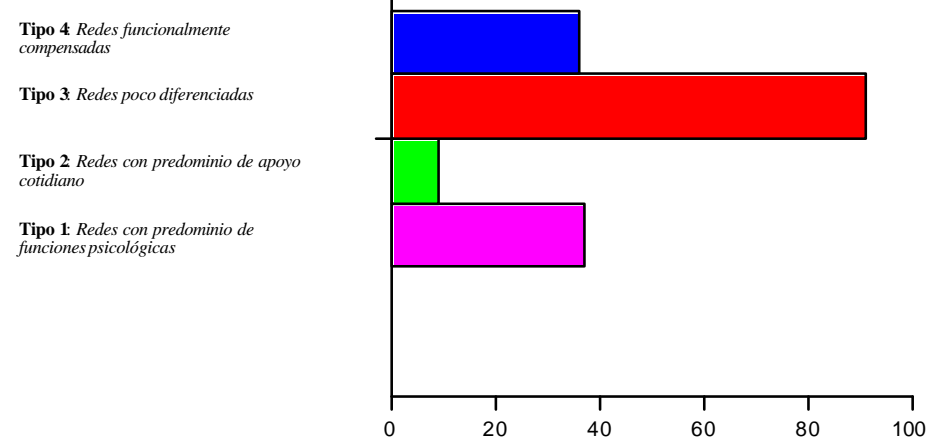

Como observamos en las Tablas 2.2 a 2.5, los conglomerados de red según las funciones de apoyo difieren significativamente por nacionalidad, género, ocupación laboral y número de familiares en España.

En las redes poco diferenciadas (Tipo 3) están significativamente representados los marroquíes, mientras que ocurre al contrario con los senegaleses y los filipinos. Es el grupo que cuenta comparativamente con más mujeres, y donde hay mayor número de divorciados(as) y viudos(as). Tienden a visitar el país de origen con mayor frecuencia que el resto, y es más probable que no contaran con antecedentes familiares cuando emigraron. De hecho, es el grupo que dispone de menos familiares en España. En lo que respecta a la ocupación laboral, predomina el servicio doméstico y es infrecuente la venta ambulante. Es menos probable que en las demás categorías disponer de permiso de trabajo.

Al contrario que la anterior, la red con predominio de funciones psicológicas (Tipo 1 ), es menos frecuente entre los marroquíes y cuenta con más hombres. Es el grupo con mayor movilidad geográfica desde que está en la península, y con mayor probabilidad de disponer de casa propia. Tienden a ocupar los intervalos superiores de ingresos económicos. Predomina el trabajo en hostelería y es comparativamente poco frecuente el servicio doméstico.

Los encuestados con redes funcionalmente compensadas (Tipo 4) son en una proporción significativa hombres y trabajadores de la venta ambulante. Es más probable que sean senegaleses y menos marroquíes.

Por último, el conglomerado con menor prevalencia, es decir el de redes con predominio de apoyo cotidiano (Tipo 2) es el que cuenta, con diferencia, con mayor número de familiares en España, y es significativo el número de ellos que se ubican en el segmento superior de ingresos mensuales.

Gráfico 6. Depresión y accesibilidad a servicios sociales según tipo de redes (funciones) 


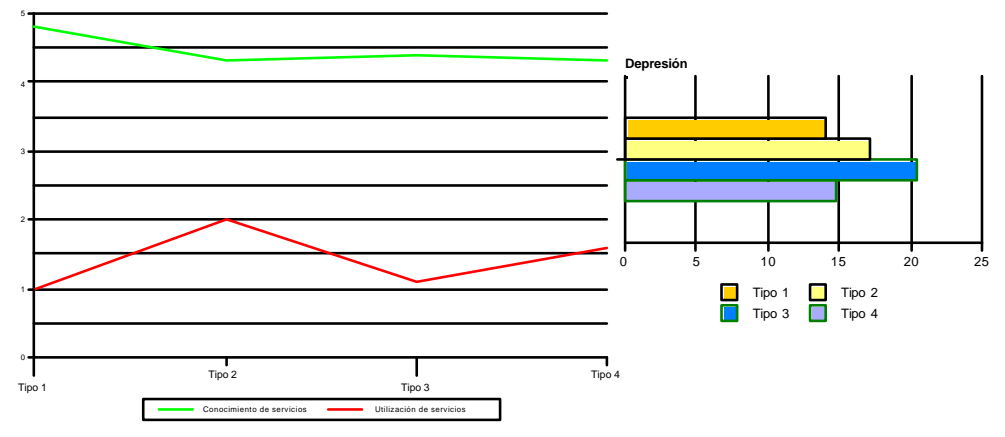

No hay diferencias en aspectos comportamentales ni de valoración del apoyo, pero sí en los indicadores de adaptación. El subgrupo de inmigrantes con redes poco diferenciadas puntúa en depresión entre 3 y 6 puntos por encima del resto como promedio. Por su parte, las redes amplias en las que predomina el apoyo cotidiano permiten una mejor accesibilidad a los servicios.

\section{Tipología según la estructura de la red personal}

Por último, realizamos una clasificación de los inmigrantes a partir de tres indicadores sobre la estructura de la red personal: el tamaño total de la red de apoyo, la multiplicidad media de los vínculos disponibles y la proporción de vínculos con funciones específicas. Multiplicidad y especificidad mantienen una relación inversa significativa, como muestra el elevado coeficiente de correlación ( $R=-.824$, $\mathrm{p}<.001$ ), pero ambas sirven para distinguir convenientemente tipos de red personal (Tabla 3.1). Esta tercera tipología exploratoria es la que da lugar a una distribución más equilibrada de los sujetos entre las cuatro categorías resultantes. A continuación describimos las características de dichos conglomerados.

Gráfico 7. Tipos de redes personales según estructura 


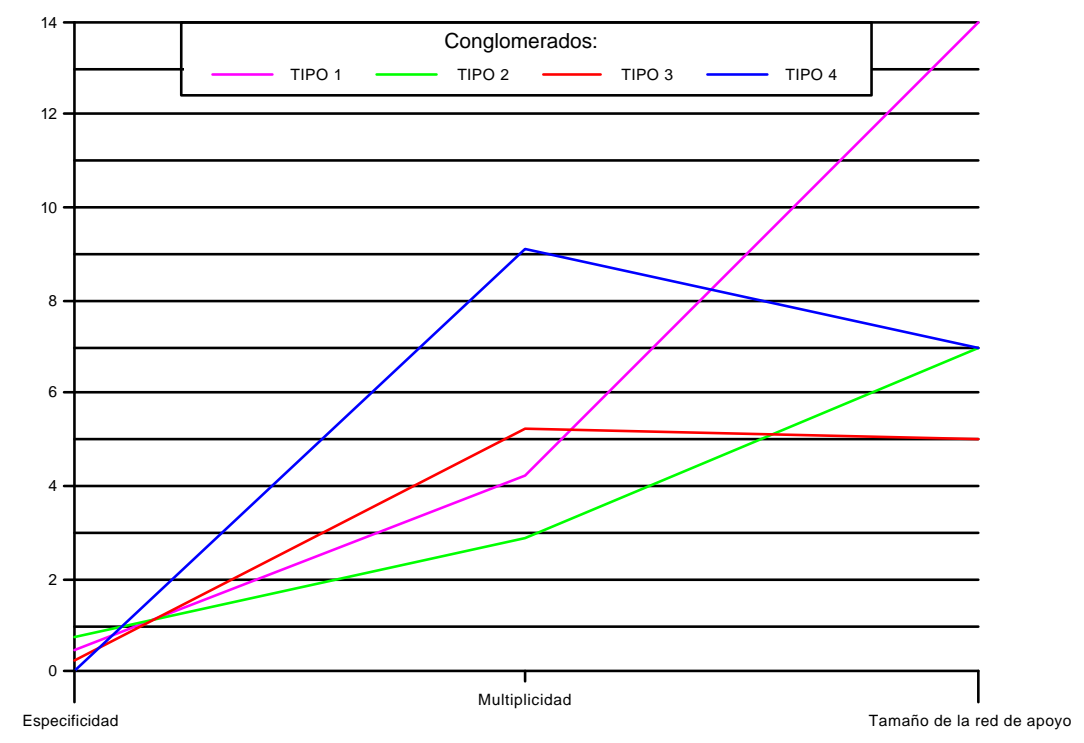

Redes pequeñas polivalentes (o concentradas) (Tipo 3). Los encuestados asignados a esta categoría concentran sus demandas de apoyo en un grupo de unos 5 vínculos. Esta red ocupa la segunda posición en cuanto al nivel de multiplicidad, lo que parece reflejar que la persona focal saca el máximo partido a los pocos contactos existentes.

Redes intermedias de vínculos especializados (o dispersas) (Tipo 2). Es la red que 
Tipo 4: Redes intermedias polivalentes (sinérgicas)

Tipo 3: Redes pequeñas polivalentes (concentradas)

Tipo 2: Redes intermedias de vínculos especializados(dispersas)

Tipo 1: Redes amplias equilibradas (integradas)

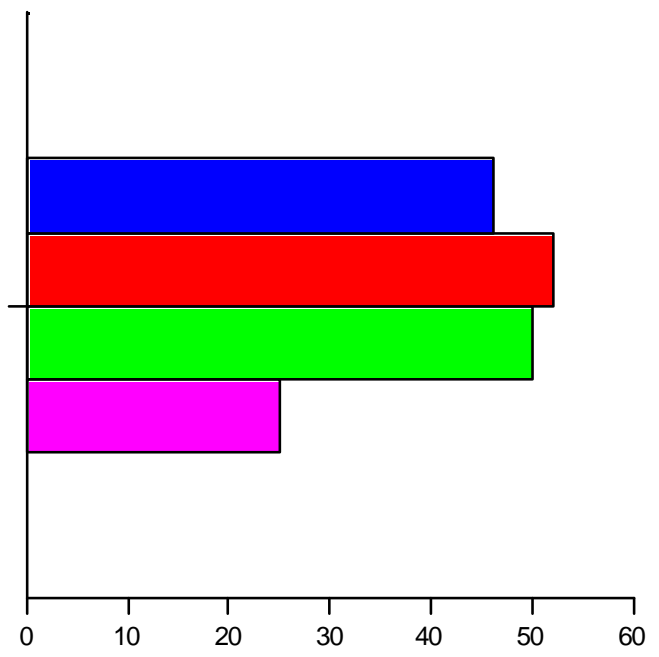

Las variables estructurales permiten distinguir conglomerados que se asocian significativamente con la nacionalidad, el proyecto migratorio, el tiempo de estancia, la ocupación laboral, el tipo de documentación en regla y el número de familiares en España (Tablas 3.2 a 3.5).

Las redes pequeñas polivalentes (Tipo 3) las han conformado aquellos que llevan menos tiempo residiendo en España. El grupo nacional en el que es más probable que se desarrollen este tipo de redes es el de los marroquíes, mientras que es comparativamente poco frecuente en los senegaleses. En este conglomerado están significativamente poco representados los solteros y los vendedores ambulantes. También hay mayor número de inmigrantes irregulares.

Las redes intermedias de vínculos especializados (Tipo 2) coinciden con la tipología anterior en una alta prevalencia de marroquíes, y son igualmente escasos senegaleses y vendedores ambulantes. Es el colectivo con mayor proporción de mujeres, alcanzando casi los dos tercios de esta submuestra. Tienden a visitar su país con algo más de frecuencia que el resto y son mayoría los que tienen una clara intención de permanecer en España.

Al contrario que las dos categorías anteriores, los encuestados con redes intermedias polivalentes (Tipo 4) son en una proporción significativa senegaleses, y están pobremente representados los marroquíes. En consonancia con ello, es el grupo con un porcentaje más alto de hombres (más de dos tercios), y tienden a ser solteros, vivir de alquiler y trabajar en la venta ambulante. Cuentan, con mucho, con el mayor número de inmigrantes que declaran su intención de retornar al país de origen. Por contra, apenas aparecen en este grupo divorciados o viudos.

Por último, el conglomerado de redes amplias equilibradas (Tipo 1) destaca del resto por el tiempo de estancia y el número de familiares en España. Como promedio llevan entre dos y cinco años más de residencia que el resto de categorías, y disponen de tres o cuatro parientes más. Tienden a visitar el país de 
origen con cierta frecuencia, y es más habitual que tengan vivienda en propiedad y (por comparación) altos ingresos. Más de un tercio de este grupo dispone de permiso comunitario.

Una vez más, no hay diferencias ni en los comportamientos de apoyo ni en la valoración del mismo, y sí en los demás indicadores. Las redes con más vínculos especializados pertenecen a los inmigrantes que más puntúan en depresión, mientras que las redes más amplias se asocian a un mejor conocimiento y mayor utilización de los servicios sociales.

Gráfico 9. Depresión y accesibilidad a servicios sociales según tipo de redes (estructura)

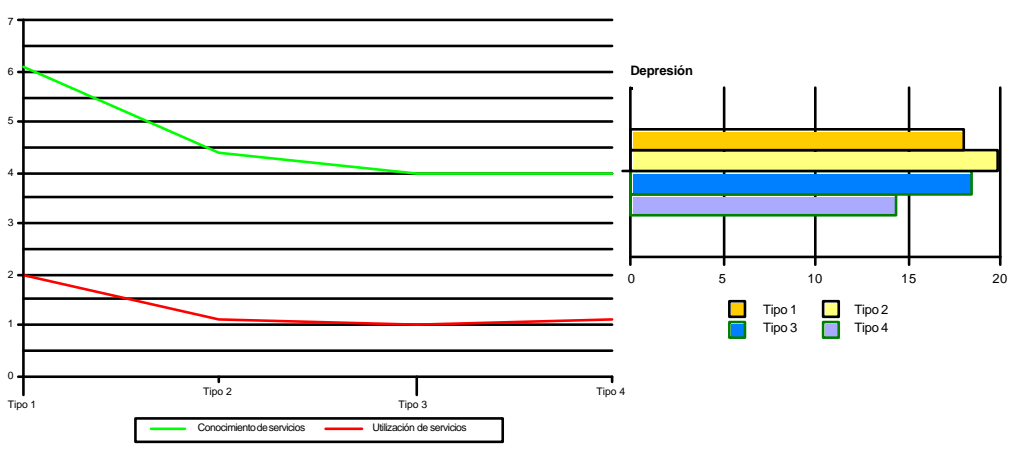

\section{Construcción de una tipología de redes personales de los inmigrantes}

\section{Selección de las variables criterio}

Antes de elaborar una tipología general utilizando indicadores estructurales, funcionales y de composición, examinamos el grado de asociación entre las tres clasificaciones anteriores. Las pruebas de chi-cuadrado ponen de manifiesto la relación significativa entre las tipologías de composición y estructura $\left(X^{2}{ }_{(9)}=96.27\right.$, $\mathrm{p}<.001)$, de composición y funciones $\left(X^{2}{ }_{(9)}=75.042, p<.001\right)$, y de estructura y funciones $\left(X^{2}{ }_{(9)}=109.317, p<.001\right)$. En los tres casos se obtienen cinco casillas en las que la proporción de sujetos supera con creces la probabilidad teórica, por lo que la solución de cinco conglomerados parece la que mejor se ajusta a los datos disponibles (Tablas 4.1 a 4.3). Las cinco categorías resultantes serían las siguientes:

1. Más de la mitad de los inmigrantes concentran sus demandas de ayuda en una pequeña red de familiares y amigos compatriotas. El limitado tamaño de la red da lugar a escasa diferenciación funcional, de forma que el grueso de los proveedores de apoyo son polivalentes. 
2. Otro grupo de inmigrantes cuenta con redes personales ligeramente superiores a la anterior, aunque coinciden en la composición familiar y étnica. La particularidad de este tipo de red radica en una elevada proporción de vínculos especializados.

3. En tercer lugar están los inmigrantes que se agrupan mayoritariamente con otros amigos compatriotas, y que recurren a ellos para cualquier tipo de necesidad personal. Esta categoría destaca por una mayor disponibilidad relativa de recursos instrumentales, y también por más recursos de ayuda en circunstancias de crisis.

4. Las dos últimas categorías corresponden a quienes han sido capaces de conformar redes amplias, constituidas por una mezcla de vínculos polivalentes y especializados. Por un lado se encuentran las redes étnicas, con predominio de familiares, que tienen además una gran disponibilidad de ayuda para las demandas del día a día.

5. Y, por último, un pequeño grupo ha establecido contactos personales con varios miembros de la comunidad receptora, y tienen particularmente bien atendidas las necesidades de naturaleza psicológica.

Gráfico 10. Construcción de una tipología general de redes personales

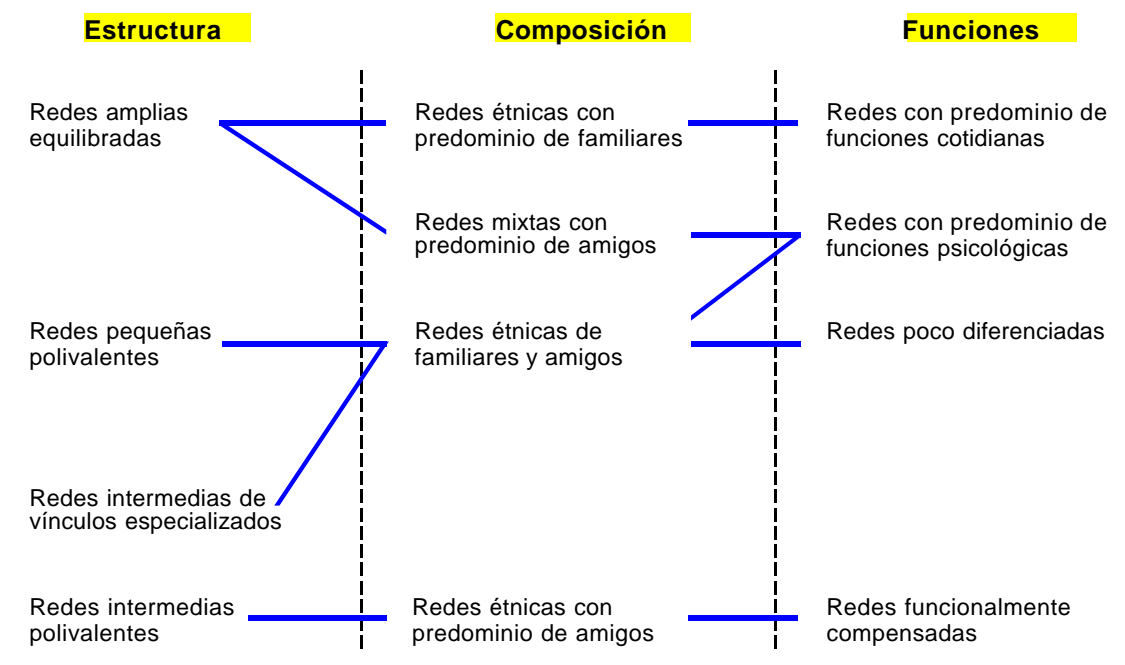

Para validar estas clases de redes personales llevamos a cabo un último Quick Cluster de cinco categorías, que se describe en el siguiente apartado. Pero antes resumimos el proceso de selección de las variables criterio.

Las variables-criterio de los análisis exploratorios están muy relacionadas entre sí. Esto conlleva graves problemas de multicolinealidad para cualquier análisis estadístico. Por ejemplo, en la clasificación en conglomerados puede ocurrir que los índices más relacionados entre sí tengan más peso que otros en la creación de categorías. Por eso el primer paso consistió en reducir el conjunto original de 11 variables a un subconjunto de indicadores menos relacionados entre sí. En 
concreto, seleccionamos a aquellas (1) que establecían una mayor diferenciación entre clusters según el ANOVA (cfr. supra), (2) que mejor reflejaban la estructura factorial de la red de apoyo social, y (3) que guardaban menos correlación con el resto de variables. La solución factorial del análisis de componentes principales con rotación Varimax se recoge en la Tabla 4.4; y la matriz de correlaciones en la Tabla 4.5.

En primer lugar optamos por no incluir como variables-criterio el tamaño de la red de apoyo ni la proporción de proveedores especializados. El tamaño mantiene una correlación superior a .60 con cuatro variables diferentes, y además satura en dos de los factores extraídos. Por su parte, la especificidad mantiene la correlación más elevada de la matriz con una segunda variable ( $r=-.824)$.

En segundo lugar eliminamos dos variables del Factor 1, para evitar que estuviese sobre-representado en análisis posteriores. En concreto excluimos dos indicadores con una correlación superior a .60: el apoyo psicológico disponible en situaciones de crisis y el apoyo instrumental cotidiano disponible.

\section{Análisis de conglomerados con variables estructurales, funcionales y de composición}

El Quick Cluster de 5 agrupaciones se derivó, por consiguiente, a partir de 7 variables criterio relativas a la red de apoyo personal: disponibilidad de ayuda cotidiana psicológica, disponibilidad de ayuda instrumental en situaciones de crisis, número de compatriotas, número de españoles, número de familiares, número de no-familiares, y multiplicidad media de los vínculos (Tabla 5.1). Las condiciones de aplicación fueron un criterio de convergencia de 0.02, y la actualización de las medias en cada paso. Se utilizaron las puntuaciones tipificadas para evitar los sesgos relativos a la unidad de medida de las variables. La convergencia se alcanzó en la quinta iteración, dando lugar a agrupaciones que, como veremos a continuación, coinciden en líneas generales con las descritas en el apartado anterior.

Gráfico 11. Tipología según variables estructurales, funcionales y de composición 


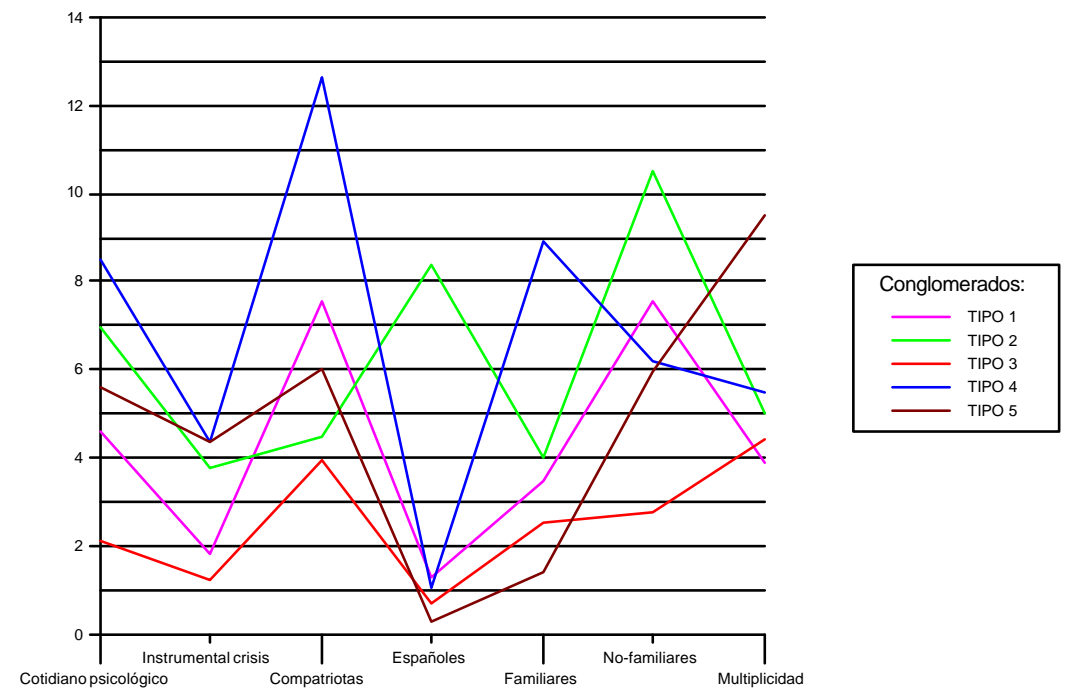

1. La estructura reticular más frecuente (44.5\%) en el colectivo estudiado podría denominarse (1) red pequeña de amigos y familiares compatriotas (Tipo 3 ). Se trata de un núcleo que apenas alcanza los cinco vínculos, formado en su mayoría por parientes y otros paisanos. Por sus características, es comparable a lo que algunos investigadores han identificado como "redes de necesidad" posteriores a la migración. Es un tipo de red que desarrollan con más frecuencia las mujeres $(61 \%)$, y que comparativamente está menos representado en el intervalo superior de ingresos. También es el conglomerado donde hay más divorciados(as) y viudos(as); y que cuenta con el promedio más elevado de depresión (en concreto, entre 2 y 7 puntos por encima del resto de categorías).

2. En segundo lugar, se encuentra un subgrupo (22.5\%) con un entorno personal bastante similar al anterior, excepto por una mayor presencia relativa de no-familiares, y por disponer de los proveedores menos polivalentes de entre los cinco clusters. Estos rasgos nos llevan a calificarlas como (2) redes étnicas con predominio de vínculos especializados (Tipo $1)$. De hecho, el tamaño promedio alcanza los nueve contactos, y más de la mitad realiza funciones específicas. Los inmigrantes asignados a este cluster superan en edad a la media de la muestra y es comparativamente poco probable que estén solteros.

3. A continuación, (3) las redes sinérgicas con predominio de amigos compatriotas (Tipo 5) las han desarrollado un quinto de los entrevistados (20.23\%). Concentran sus demandas de apoyo en un grupo de amigos, a los que recurren para cualquier tipo de problema. Como contraste, la proporción de españoles y de familiares es la menos 
representativa de los cinco conglomerados. Los proveedores de esta red personal cubren por lo general todas las funciones posibles, y tan alto grado de polivalencia se refleja en una inhabitual disponibilidad de recursos instrumentales $y$ de crisis. Pertenecen a este grupo los inmigrantes con una media de edad más alta (41 años). Los hombres predominan sobre las mujeres, y un amplio porcentaje se dedica a la venta ambulante $(40 \%)$. Más de la mitad tiene permiso de trabajo. Es con diferencia el colectivo donde más entrevistados declaran su intención de retornar al país de origen (46.7\%), y que con menos frecuencia lo han visitado desde que están en España.

4. Las dos últimas categorías corresponden a quienes tienen avanzado el proceso de reagrupamiento familiar, pues cuentan con unos ocho parientes residiendo en España. Por un lado, están las (4) redes étnicas de reagrupamiento familiar (Tipo 4), que son las únicas en las que la proporción de familiares supera a la de no-familiares. Y por otro las (5) redes de reagrupamiento familiar integradas en la comunidad receptora (Tipo 2): se trata de un pequeño grupo de entrevistados $(4.62 \%)$ que también dispone de un núcleo de familiares, pero en el que lo más llamativo es el gran número de relaciones personales de apoyo que han establecido con españoles.

Ambas conforman las redes personales más amplias, con unos 14 vínculos. Las primeras corresponden a un segmento de inmigración estable, con el porcentaje más alto de permisos comunitarios, que tiene intención de permanecer en España (100\%) y es más probable que posea una casa en propiedad. Por su parte, las redes integradas localmente corresponden a hombres, significativamente más jóvenes que el promedio de la muestra, y con una alta probabilidad solteros. En coincidencia con este perfil, no hay ningún empleado del servicio doméstico. También es característico la elevada frecuencia de intercambios de apoyo, que les diferencia del resto.

Consideradas conjuntamente, las redes de reagrupamiento (Tipos 2 y 4 ) se asocian con un mayor uso de servicios sociales $\left(F_{(3,169)}=3.02, p<.031\right)$ : en concreto, han utilizado como promedio dos prestaciones sociales desde que están en España (frente al resto, que sólo han hecho uso de una).

Gráfico 12. Porcentaje con cada tipo de red 


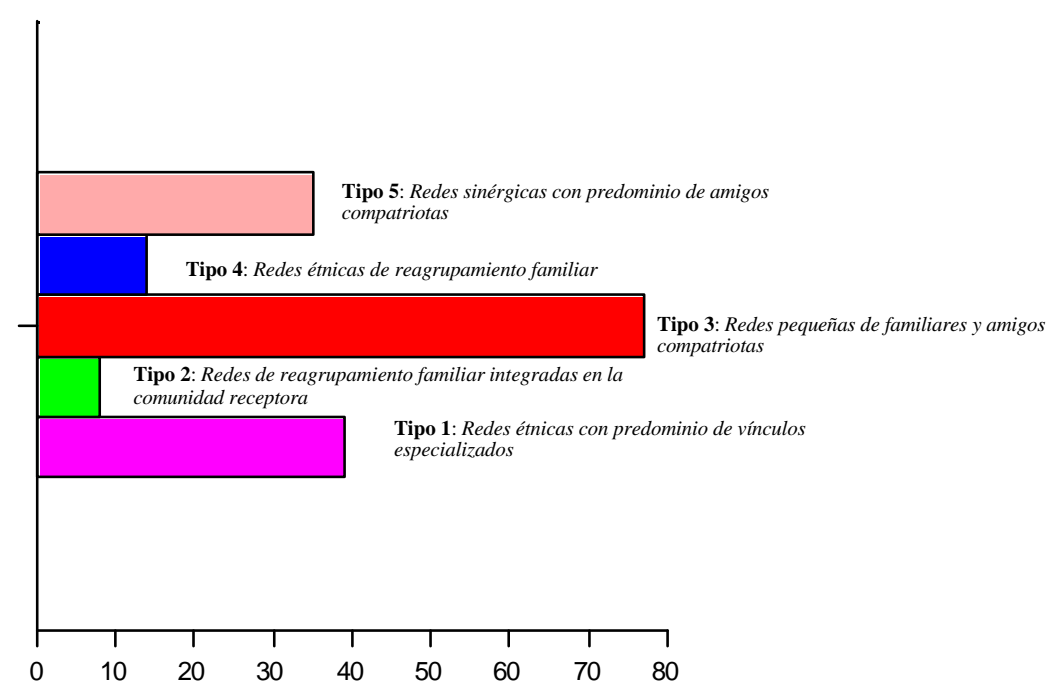

El tipo de cluster guarda relación significativa con la nacionalidad, la ocupación laboral, el número de familiares en España, los planes de futuro, la edad, el estado civil y el género (Tablas 5.2 a 5.5).

Los tres colectivos estudiados tienen un perfil claramente diferenciado en sus redes personales. Por ejemplo, el $60 \%$ de los marroquíes se ubica en la categoría de redes más pequeñas (Tipo 3 ), mientras que el $60 \%$ de los senegaleses se asocia en grupos de compatriotas polivalentes (Tipo 5). Los filipinos están más repartidos entre las cinco categorías. Sin embargo, están por debajo de lo esperado en las redes pequeñas y significativamente representados en las redes étnicas de reagrupamiento.

Gráfico 13. Accesibilidad a servicios sociales por tipo de red 


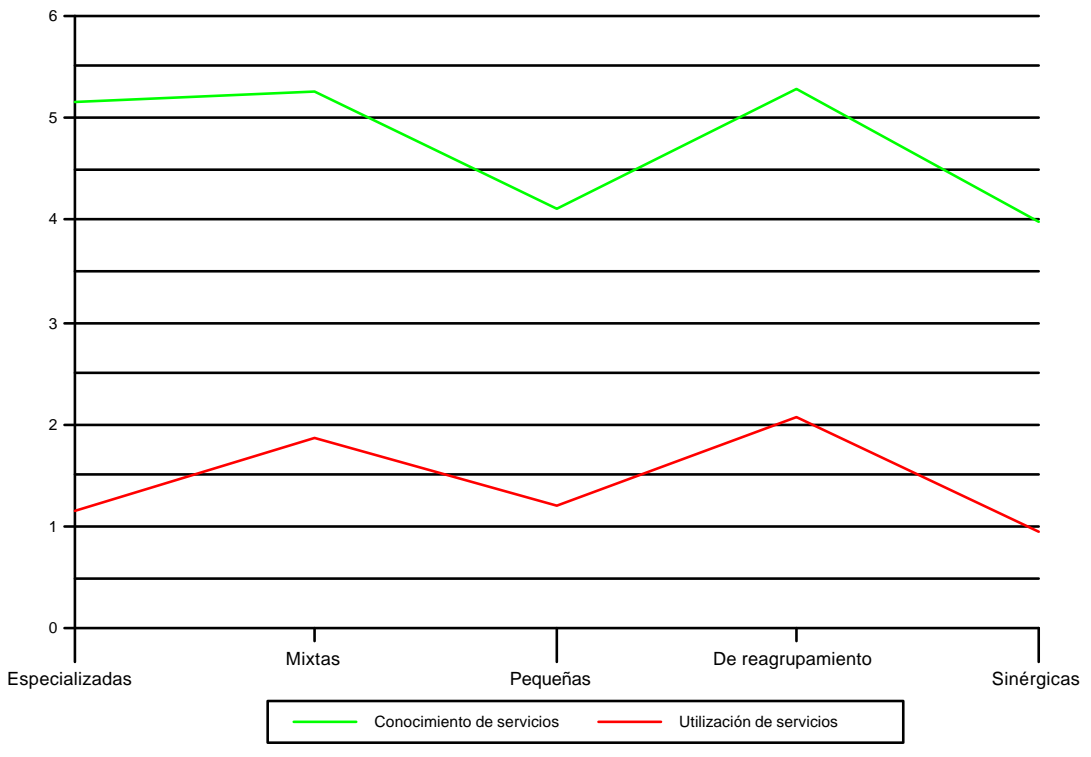

Gráfico 14. Depresión por tipo de red

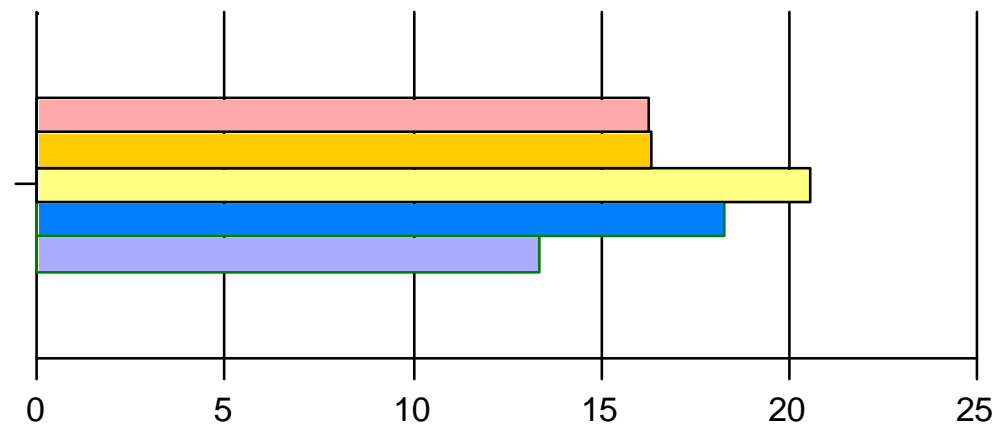

Redes especializadas

Redes mixtas de reagrupamiento

Redes pequeñas

Redes étnicas de reagrupamiento

Redes sinérgicas de compatriotas

\section{Conclusiones}

La elaboración de tipologías de redes de apoyo por medio del análisis de conglomerados es una herramienta útil para distinguir los entornos interpersonales 
de los inmigrantes, y contribuye a la comprensión tanto de los patrones de acceso a servicios sociales como de la adaptación subjetiva en el nuevo contexto:

1. El grueso de los inmigrantes ve afectadas sus redes de apoyo tras el desplazamiento, de forma que tienen una menor disponibilidad de ayuda en caso de necesidad. Un pequeño grupo de familiares y amigos compatriotas es la estructura reticular más prevalente, y coincide con aquellos encuestados que obtienen puntuaciones más elevadas en depresión.

2. Las redes de apoyo están compuestas de forma predominante por miembros del propio grupo étnico, amigos o familiares. Tanto la lógica propia de las cadenas migratorias como la segregación social en el contexto receptor podrían estar condicionando dicho resultado. Los individuos capaces de desarrollar contactos personales con españoles son hombres, jóvenes y solteros.

3. El proceso de reagrupamiento familiar se desarrolla a medida que el inmigrante lleva más tiempo residiendo en España, y es clave en la conformación de redes personales amplias y equilibradas. Tanto la estabilidad del proyecto migratorio como la constitución de redes personales más extensas se producen paralelamente a un mejor conocimiento y mayor accesibilidad a los servicios sociales. Las redes de apoyo parecen ejercer un papel facilitador del uso de prestaciones.

4. Existe una clara relación entre el grupo étnico y el tipo de red personal: los marroquíes disponen en su mayoría de redes pequeñas, y los senegaleses suelen concentrar todas sus demandas de ayuda en un grupo de compatriotas. El colectivo filipino es el que muestra más diferencias intragrupo al respecto. Es frecuente que los senegaleses se asocien en grupos que funcionan de modo auto-suficiente, y es llamativo que en ellos coincidan los índices menores de utilización de servicios y la menor incidencia de depresión.

5. A grandes rasgos, la tipología descrita coincide con los hallazgos de estudios anteriores (Litwin, 1995, 1997a, 1997b).

\section{E. Referencias bibliográficas}

ANGEL, J. L. y ANGEL, R. J. (1992): Age at migration, social connections, and wellbeing among elderly Hispanics. Journal of Aging and Health; Nov, vol.4 (4) 480499.

BATES, T. (1994): Social Resources Generated by Group Support Networks May Not Be Beneficial to Asian Immigrant-Owned Small Businesses. Social Forces, 72, 3, march, 671-689.

BIALIK-GILAD, R. (1988): The effects of immigration on social support networks of older salvadorans. Dissertation Abstracts International, 1990, 51, 1, July, 293-A.

DASGUPTA, S. (1992): Conjugal roles and social network in Indian immigrant families: Bott revisited. Journal of Comparative Family Studies, Fal. Vol. 23 (3), 465-480. 
DINH, K. T., SARASON, B. R. y SARASON, I. G. (1994): Parent-child relationships in Vietnamese immigrant families. Journal of Family Psychology, Dec., vol.8,4, 471488.

EATON, W. y KESSLER, L. (1981): Rates of symptoms of depression in a national sample. American Journal of Epidemiology, 114, 528-538.

FERRER, E. y RODRÍGUEZ, A. (1999): Estudio descriptivo de la patología depresiva en la atención primaria gallega. Anales de Psiquiatría, 15 (2), 68- 75.

FRANKS, F. y FAUX, S. A. (1990): Depression, stress, mastery, and social resources in four ethnocultural women's groups. Research in Nursing and Health; Oct, vol. 13 (5) 282-292.

FULIGNI, A. J. (1997): The academic achievement of adolescents from immigrant families: the role of family background, attitudes and behavior. Child Development, vol. 68 (2), 351-363.

GREENWELL, L., VALDEZ, R. B. y DA VANZO, J. (1997): Social ties, wages, and gender in a study of Salvadorean and Pilipino immigrants in Los Angeles. Social Science Quarterly, vol.78, 2, 559-577.

HERNÁNDEZ, E. y GILBERT, L. A. (1987): Social support networks for parenting and psychological well-being among dual-earner Mexican-American families. Journal of Community Psychology, vol.15, Apr., 176-185.

HOVEY, J. D. (1999): Moderating influence of social support on suicidal ideation in a sample of Mexican immigrants. Psychological Reports, 8 (1), 78- 79.

IMA, K. y HOHM, C. F. (1991): Child maltreatment among Asian and Pacific Islander refugees and immigrants: The San Diego case. Journal of Interpersonal Violence, Sep Vol 6(3) 267-285.

JON, S. H. (1998): Consequences of acculturative stress and social support on depression among adult Korean immigrants. Dissertation Abstracts International. The Science and Engineering, 58 (7- B), 3558.

JOU, Y. H. y FUKADA, H. (1996): Influences of social supports and personality on adjustment of Chinese students in Japan. Journal of Applied Social Psychology, Vol.26, 20, pp.1795-1802.

LAI, D. W. y MCDONALD, J. R. (1995): Life satisfaction of Chinese elderly immigrants in Calgary. Canadian Journal on Aging, vol.14, 3, 536-552. 
LITWIN, H. (1995): The social networks of elderly immigrants: An analytic typology. Journal of Aging Studies, Sum Vol 9(2) 155-174.

LITWIN, H. (1997a): The networks shifts of eldery immigrants: the case of Soviet Jews in Israel. Journal of Cross-Cultural Gerontology, 12, 45-60.

LITWIN, H. (1997b): Support network type and health service utilization. Research on aging, vol. 19 (3), 274- 299.

MAYA, I. (1999): Análisis de los recursos de apoyo social de los inmigrantes africanos y latinoamericanos en Andalucía. Tipología de redes y proceso de adaptación. Tesis doctoral. Departamento de Psicología Social, Universidad de Sevilla.

FUDGE, H., NEUFELD, A., HARRISON, M. J. (1997): Social networks of women caregivers. Public Health Nursing, 14 (1), 20-27.

PETERSON, J., FOLKMAN, S. y BAKEMAN, R. (1996): Stress, coping, HIV status, psychosocial resources, and depressive mood in African gay, bisexual and heterosexual men. American Journal of Community Psychology, 24 (4), 461- 487.

RADLOFF, L. (1977): The CES-D scale: a self report depression scale for research in the general population. Appl. Psychol. Meas. 1, 385-401.

SÁNCHEZ, J. I. y VISCARRA, D. M. (1995): Are hispanic employees unwilling to relocate? The case of south Florida. International Journal of Intercultural Relationships, vol.19, № 1, 45-58.

SASAO, T. y CHUN, C. A. (1994): After the Sa-i-gu (April 29) Los Angeles Riots: correlates of subjective well-being in the Korean-American Community. Journal of Community Psychology, vol.22, pp. 136-152.

SCHÖNPFLUG, U., SILBEREISEN, R. K., y SCHULZ, J. (1990): Perceived decision making influence in Turkish migrant workers' and German workers' families: The impact of social support. Journal of Cross Cultural Psychology, Sep. Vol. 21 (3), 261-282.

SCHWARZER, R. y HAHN, A. (1995): Reemployment after migration from East to West Germany: A longitudinal study on psychosocial factors. Applied Psychology An International Review; Jan Vol 44(1) 77-93.

SHERRADEN, M. S. y BARRERA, R. E. (1996): Maternal support and cultural influences among Mexican immigrant mothers. Families in Society, vol.77, 5, 298313. 
SOleR, J., PÉREZ, V., PUIGdemont, D., PÉREZ, J., FIGUeReS, M. Y ÁlVAReZ, E. (1997): Estudio de validación del CES-D en una población española de pacientes con trastornos afectivos. Actas Luso-Españolas de Neurología, Psiquiatría y Ciencias Afines, 25(4), 243-249.

TAFT, R. (1986): Methodological considerations in the study of immigrant adaptation in Australia. Australian Journal of Psychology, Dec. Vol.38 (3) 339-346.

TYLER, F. B., TYLER, S. L., TOMMASELLO, A., y ZHANG, Y. (1992): Psychosocial characteristics of marginal immigrant Latino youth. Youth and Society, Sep. Vol. 24 (1), 92632 T415 0 TD 8.0735 Tc 0 Tw (-) Tj 4.50 TD -1Tj 8 Tc (249.) Tj 21.250 TD /F4 9.75 Tf 
Redes - Revista Hispana para el análisis de redes sociales. Volumen 1\#4

Tabla 1.1. Medias y análisis oneway de la varianza de las variables de apoyo por tipo de red

Tipo de red de

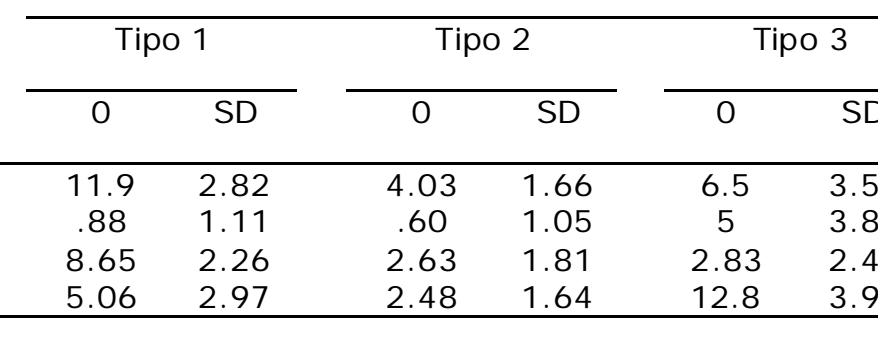

$* * * \mathrm{p}<.001$ 
Tabla 1.2. Características sociodemográficas de los inmigrantes por tipo de red

Tipo de red de apo

\begin{tabular}{ll}
\hline \multicolumn{2}{c}{ Tipo 1 } \\
\end{tabular}

\begin{tabular}{|c|c|c|c|c|c|c|}
\hline Edad & 35 & 9.6 & 37.3 & 14.1 & 29.8 & 9 \\
\hline Año de entrada & 84.3 & 7.2 & 89.1 & 6.3 & 88.6 & 5.6 \\
\hline \multirow[t]{2}{*}{ Años de escolarización } & 10 & 4 & 9.7 & 3.6 & 9 & 4. $]$ \\
\hline & $\mathrm{N}$ & $\%$ & $\mathrm{~N}$ & $\%$ & $\mathrm{~N}$ & $\overline{\%}$ \\
\hline \multicolumn{7}{|l|}{ Género } \\
\hline Hombre & 7 & 41.2 & 36 & 41.9 & 13 & 72.2 \\
\hline Mujer & 10 & 58.8 & 50 & 58.1 & 5 & $28 . \xi$ \\
\hline \multicolumn{7}{|l|}{ Estado civil } \\
\hline Soltero & 3 & 17.6 & 20 & 23.3 & 9 & 50: \\
\hline Casado/Pareja & 14 & 82.4 & 56 & 65.1 & 8 & 44.2 \\
\hline Divorciado/Viudo & - & - & 10 & 11.6 & 1 & 5.6 \\
\hline \multicolumn{7}{|l|}{ Nacionalidad } \\
\hline Marroquí & 7 & 41.2 & 49 & $57 *$ & 7 & 38. \\
\hline Senegalesa & - & - & 6 & $7 *$ & 5 & 27.8 \\
\hline Filipina & 10 & 58.8 & 31 & 36 & 6 & 33. \\
\hline \multicolumn{7}{|l|}{ Documentación en regla } \\
\hline Permiso de residencia & 3 & 18.8 & 38 & $44.2 *$ & 5 & 27. \\
\hline Permiso de trabajo & 7 & 43.8 & 25 & $29.1 *$ & 7 & 38. \\
\hline Como turista & - & - & 1 & 1.2 & - & - \\
\hline Tarjeta de estudiante & - & - & 4 & $4.7 *$ & - & - \\
\hline I rregular o en contencioso & 2 & 12.5 & 8 & 9.3 & 1 & 5.6 \\
\hline Permiso comunitario & 4 & 25 & 10 & 11.6 & 5 & 27. \\
\hline
\end{tabular}


Redes - Revista Hispana para el análisis de redes sociales. Volumen 1\#4

Tabla 1.3. Movilidad geográfica y tipo de vivienda por tipo de red

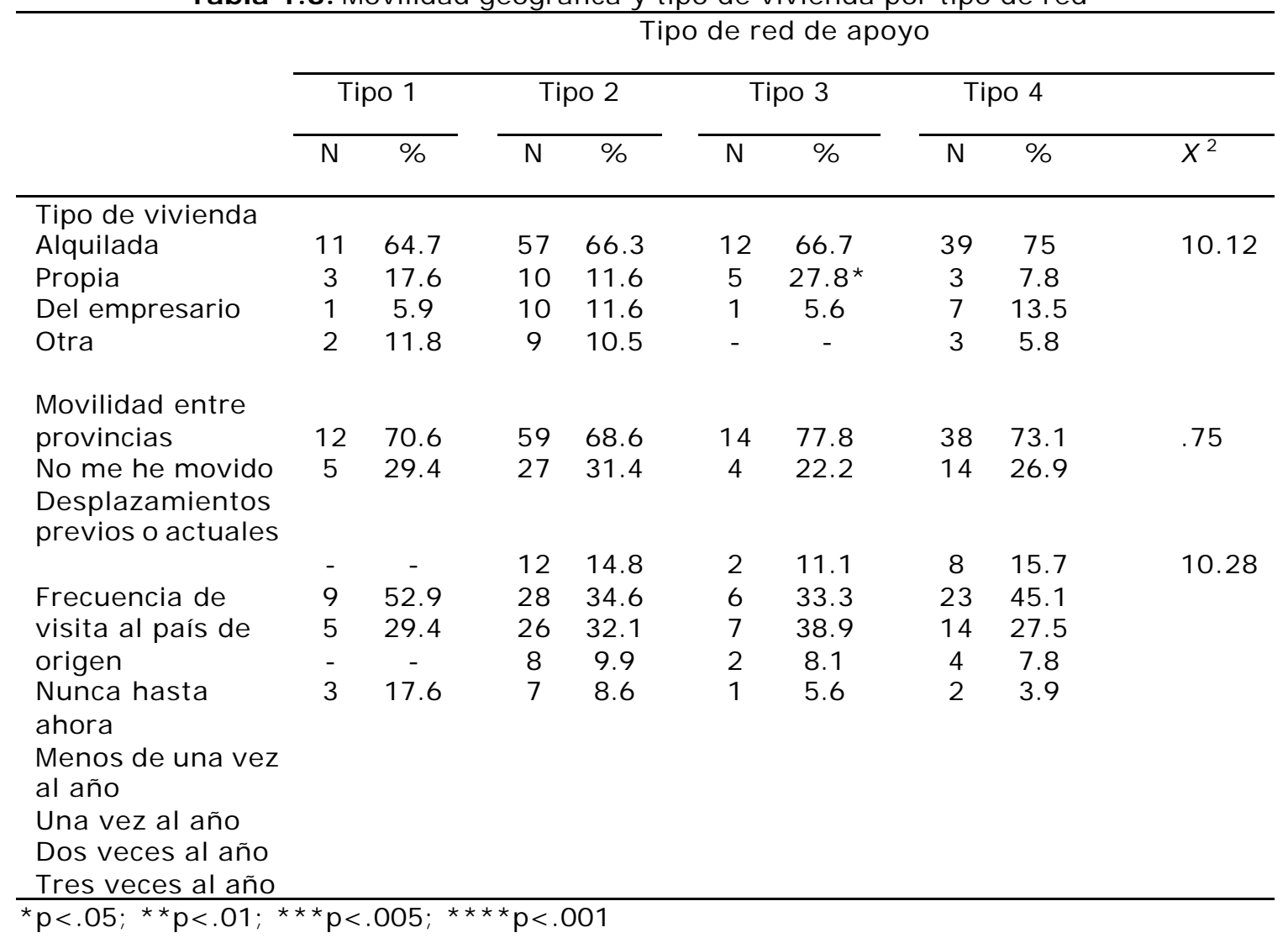


Redes - Revista Hispana para el análisis de redes sociales. Volumen 1\#4

Tabla 1.4. Situación socioeconómica por tipo de red

\begin{tabular}{|c|c|c|c|c|c|c|c|c|c|}
\hline & \multicolumn{9}{|c|}{ Tipo de red de apoyo } \\
\hline & \multicolumn{2}{|c|}{ Tipo 1} & \multicolumn{2}{|c|}{ Tipo 2} & \multicolumn{2}{|c|}{ Tipo 3} & \multicolumn{2}{|c|}{ Tipo 4} & \multirow[b]{2}{*}{$x^{2}$} \\
\hline & $\mathrm{N}$ & $\%$ & $\mathrm{~N}$ & $\%$ & $\mathrm{~N}$ & $\%$ & $\mathrm{~N}$ & $\%$ & \\
\hline \multicolumn{10}{|l|}{ Ingresos } \\
\hline mensuales & 3 & 18.8 & 23 & 28.8 & 2 & 14.3 & 9 & 19.1 & 24.19 \\
\hline Sin ingresos & - & - & 1 & 1.3 & 1 & 7.1 & 1 & 2.1 & \\
\hline Menos de & - & - & 13 & 16.3 & 2 & 14.3 & 7 & 14.9 & \\
\hline 30.000 & 6 & 37.5 & 25 & 31.3 & 1 & $7.1^{*}$ & 17 & 36.2 & \\
\hline Entre 31 y & 3 & 18.8 & 8 & 10 & 2 & 14.3 & 10 & 21.3 & \\
\hline 60 & 4 & 25 & 10 & 12.5 & 6 & $42.9 *$ & 3 & $6.4^{*}$ & \\
\hline \multicolumn{10}{|l|}{$\begin{array}{l}\text { Entre } 61 \text { y } \\
90\end{array}$} \\
\hline Entre 91 y & 3 & 17.6 & 8 & 9.3 & 4 & 22.2 & 7 & 13.5 & $34.74 * * * *$ \\
\hline 120 & 8 & 47.1 & 27 & 31.4 & - & $-*$ & 19 & 36.5 & \\
\hline \multirow[t]{2}{*}{ Más de 120} & - & - & 5 & $5.8^{*}$ & 6 & 33.3* & 12 & $23.1^{*}$ & \\
\hline & 2 & 11.8 & 16 & $18.6 *$ & - & -* & 5 & 9.6 & \\
\hline $\begin{array}{l}\text { En qué } \\
\text { trabajas } \\
\text { Hostelería }\end{array}$ & 4 & 23.5 & 30 & 34.9 & 8 & 44.4 & 9 & $17.3^{*}$ & \\
\hline $\begin{array}{l}\text { Servicio } \\
\text { doméstico }\end{array}$ & & & & & & & & & \\
\hline $\begin{array}{l}\text { Venta } \\
\text { ambulante }\end{array}$ & & & & & & & & & \\
\hline Paro & & & & & & & & & \\
\hline Otros & & & & & & & & & \\
\hline
\end{tabular}


Redes - Revista Hispana para el análisis de redes sociales. Volumen 1\#4

Tabla 1.5. Características de las cadenas migratorias y proyecto migratorio por tipo de red

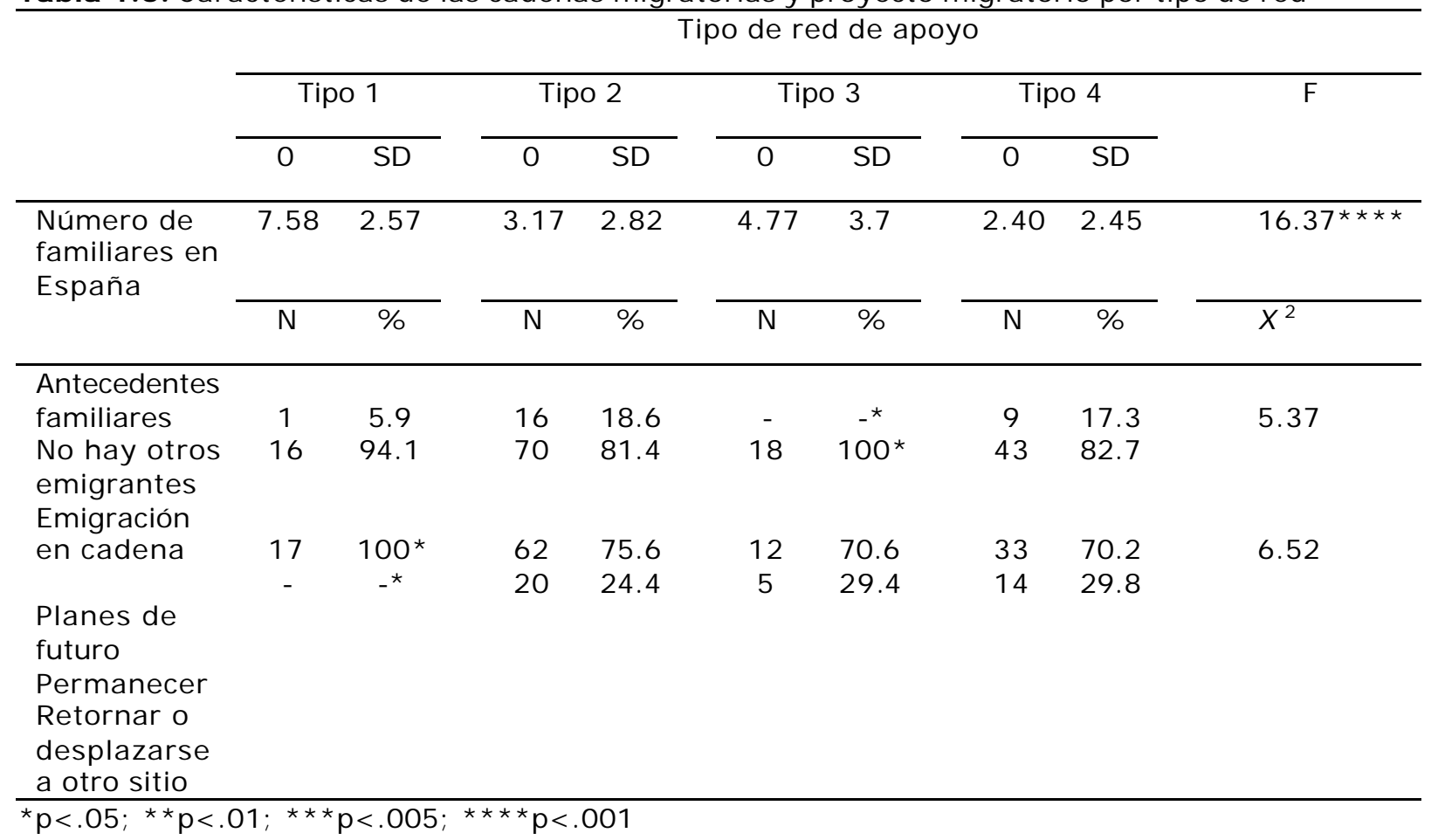


Redes - Revista Hispana para el análisis de redes sociales. Volumen 1\#4

Tabla 1.6. Medias y análisis oneway de la varianza de comportamientos de apoyo y evaluación del apoyo por tipo de red

\begin{tabular}{|c|c|c|c|c|c|c|}
\hline & \multicolumn{6}{|c|}{ Tipo de red de apo } \\
\hline & \multicolumn{2}{|c|}{ Tipo 1} & \multicolumn{2}{|c|}{ Tipo 2} & \multicolumn{2}{|c|}{ Tipo 3} \\
\hline & 0 & SD & 0 & SD & 0 & SD \\
\hline \multicolumn{7}{|l|}{ COMPORTAMIENTOS DE APOYO } \\
\hline Apoyo otorgado & 17.6 & 4.9 & 16.2 & 6.5 & 18.9 & 7.3 \\
\hline Apoyo recibido & 21.5 & 5.8 & 19.7 & 6.7 & 21.4 & 7.7 \\
\hline Ratio de apoyo otorgado/recibido & .85 & .23 & .86 & .31 & .88 & .22 \\
\hline \multicolumn{7}{|l|}{ VALORACIÓN DEL APOYO } \\
\hline $\begin{array}{l}\text { Satisfacción } \\
\text { Suficiencia }\end{array}$ & $\begin{array}{l}.87 \\
28.9\end{array}$ & $\begin{array}{l}.23 \\
5.7\end{array}$ & $\begin{array}{r}.97 \\
25.9\end{array}$ & $\begin{array}{l}.13 \\
8.3\end{array}$ & $\begin{array}{c}.94 \\
27.6\end{array}$ & $\begin{array}{l}.00 \\
4.8\end{array}$ \\
\hline
\end{tabular}


Redes - Revista Hispana para el análisis de redes sociales. Volumen 1\#4

Tabla 1.7. Bienestar, número de problemas y utilización de servicios

\begin{tabular}{|c|c|c|c|c|c|c|}
\hline & \multicolumn{6}{|c|}{ Tipo de red de a } \\
\hline & \multicolumn{2}{|c|}{ Tipo 1} & \multicolumn{2}{|c|}{ Tipo 2} & \multicolumn{2}{|c|}{ Tipo 3} \\
\hline & 0 & SD & 0 & SD & 0 & $\overline{\mathrm{SC}}$ \\
\hline Depresión & 18.3 & 7.7 & 19.4 & 9.3 & 17 & $\overline{7.6}$ \\
\hline Número de problemas percibidos & 26.5 & 7.4 & 27 & 5.8 & 27 & 6. \\
\hline Número de servicios que conoce & 5.3 & 2.4 & 4.2 & 2.6 & 5.3 & 2 \\
\hline \multirow[t]{2}{*}{ Número de servicios utilizados } & 2.1 & 1.9 & 1.1 & 1.3 & 1.8 & 1.5 \\
\hline & $\mathrm{N}$ & $\%$ & $\mathrm{~N}$ & $\%$ & $\mathrm{~N}$ & $\%$ \\
\hline \multicolumn{7}{|c|}{ Satisfacción con las circunstancias actuales } \\
\hline Algo & 2 & 11.8 & 8 & 9.3 & - & - \\
\hline Intermedio & 8 & 47.1 & 50 & 58.1 & 12 & 66. \\
\hline Mucho & 7 & 41.2 & 28 & 32.6 & 6 & 33. \\
\hline
\end{tabular}


Redes - Revista Hispana para el análisis de redes sociales. Volumen 1\#4

Tabla 2.1. Medias y análisis oneway de la varianza de las variables de apoyo por tipo de red

Tipo de red de a

\begin{tabular}{|c|c|c|c|c|c|}
\hline \multicolumn{2}{|c|}{ Tipo 1} & \multicolumn{2}{|c|}{ Tipo 2} & \multicolumn{2}{|c|}{ Tipo 3} \\
\hline 0 & SD & 0 & SD & 0 & $\overline{S C}$ \\
\hline 6.32 & 2.07 & 10.5 & 2.09 & 2.10 & 1.1 \\
\hline 2.22 & 1.73 & 9.67 & 2.34 & 1.77 & 1.3 \\
\hline 2.53 & 1.27 & 5.97 & 3.2 & 1.31 & 0.7 \\
\hline 3.21 & 1.86 & 7.44 & 2.38 & 1.71 & 1.0 \\
\hline
\end{tabular}

Apoyo cotidiano psicológico

Apoyo cotidiano instrumental

Apoyo de crisis instrumental

Apoyo de crisis psicológico

$* * * \mathrm{p}<.001$ 
Tabla 2.2. Características socio-demográficas de los inmigrantes por tipo de red

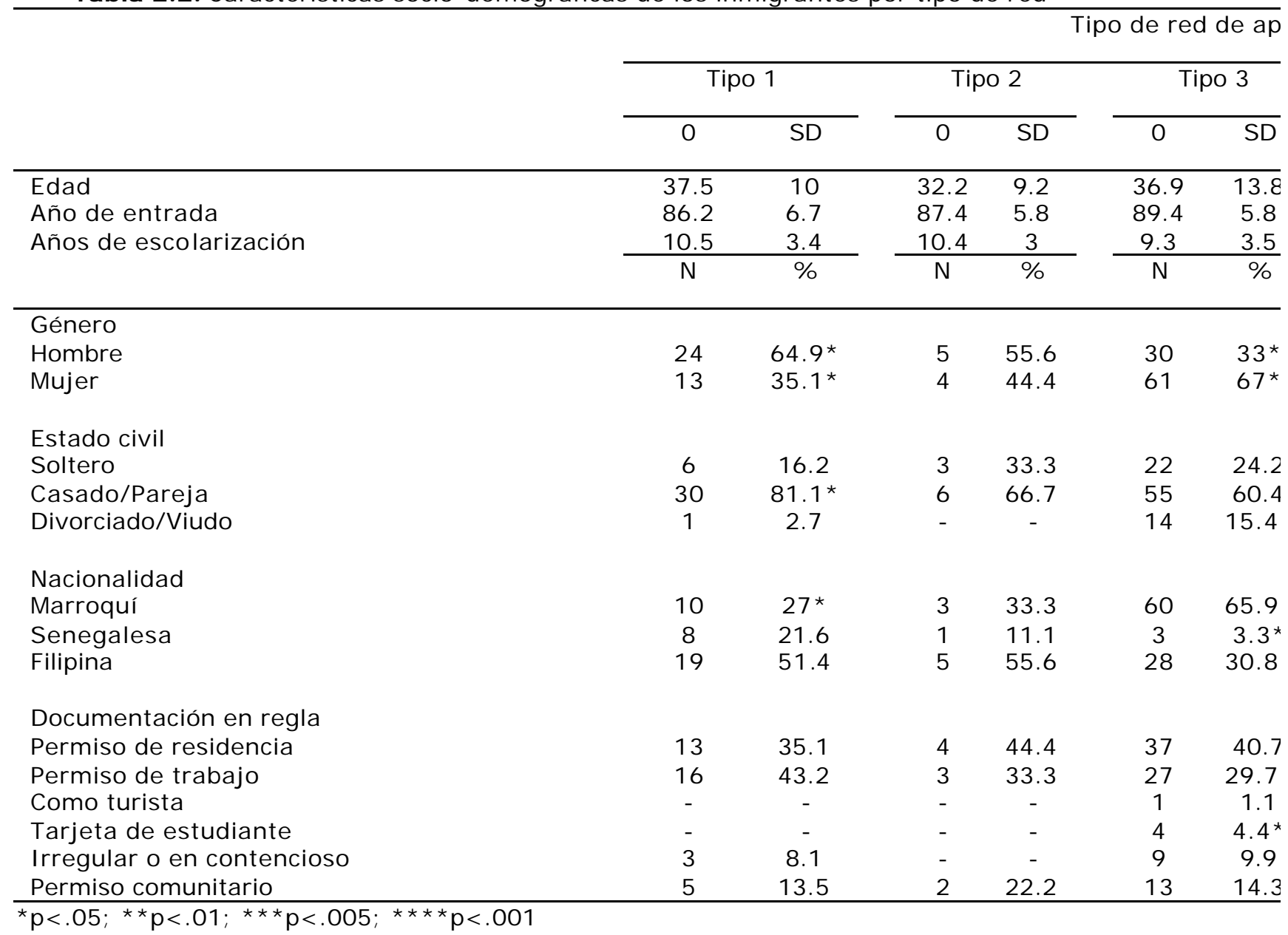


Redes - Revista Hispana para el análisis de redes sociales. Volumen 1\#4

Tabla 2.3. Movilidad geográfica y tipo de vivienda por tipo de red

\begin{tabular}{|c|c|c|c|c|c|c|c|c|c|}
\hline & \multicolumn{9}{|c|}{ Tipo de red de apoyo } \\
\hline & \multicolumn{2}{|c|}{ Tipo 1} & \multicolumn{2}{|c|}{ Tipo 2} & \multicolumn{2}{|c|}{ Tipo 3} & \multicolumn{2}{|c|}{ Tipo 4} & \multirow[b]{2}{*}{$x^{2}$} \\
\hline & $\mathrm{N}$ & $\%$ & $\mathrm{~N}$ & $\%$ & $\mathrm{~N}$ & $\%$ & $\mathrm{~N}$ & $\%$ & \\
\hline Tipo de vivienda & & & & & & & & & \\
\hline Alquilada & 26 & 70.3 & 6 & 66.7 & 60 & 65.9 & 27 & 75 & 11.71 \\
\hline Propia & 8 & $21.6 *$ & 1 & 11.1 & 10 & 11 & 2 & 5.6 & \\
\hline Del empresario & 3 & 8.1 & - & - & 12 & 13.2 & 4 & 11.1 & \\
\hline Otra & - & $-*$ & 2 & 22.2 & 9 & 9.9 & 3 & 8.3 & \\
\hline $\begin{array}{l}\text { Movilidad entre } \\
\text { provincias } \\
\text { No me he movido }\end{array}$ & $\begin{array}{l}22 \\
15\end{array}$ & $\begin{array}{l}59.5^{*} \\
40.5^{*}\end{array}$ & $\begin{array}{l}6 \\
3\end{array}$ & $\begin{array}{l}66.7 \\
33.3\end{array}$ & $\begin{array}{l}66 \\
25\end{array}$ & $\begin{array}{l}72.5 \\
27.5\end{array}$ & $\begin{array}{c}29 \\
7\end{array}$ & $\begin{array}{l}80.6 \\
19.4\end{array}$ & 4.18 \\
\hline & 2 & 5.9 & - & - & 13 & 14.6 & 7 & 20 & 13.26 \\
\hline $\begin{array}{l}\text { Frecuencia de } \\
\text { visita al país de }\end{array}$ & $\begin{array}{l}17 \\
11\end{array}$ & $\begin{array}{c}50 \\
32.4\end{array}$ & $\begin{array}{l}5 \\
3\end{array}$ & $\begin{array}{l}55.6 \\
33.3\end{array}$ & $\begin{array}{l}28 \\
30\end{array}$ & $\begin{array}{l}31.5^{*} \\
33.7\end{array}$ & $\begin{array}{c}16 \\
8\end{array}$ & $\begin{array}{l}45.7 \\
22.9\end{array}$ & \\
\hline origen & 1 & 2.9 & 1 & 11.1 & 11 & $12.4^{*}$ & 1 & 2.9 & \\
\hline $\begin{array}{l}\text { Nunca hasta } \\
\text { ahora } \\
\text { Menos de una vez } \\
\text { al año } \\
\text { Una vez al año } \\
\text { Dos veces al año } \\
\text { Tres veces al año }\end{array}$ & 3 & 8.8 & - & - & 7 & 7.9 & 3 & 8.6 & \\
\hline
\end{tabular}


Redes - Revista Hispana para el análisis de redes sociales. Volumen 1\#4

Tabla 2.4. Situación socioeconómica por tipo de red

\begin{tabular}{|c|c|c|c|c|c|c|c|c|c|}
\hline & \multicolumn{9}{|c|}{ Tipo de red de apoyo } \\
\hline & \multicolumn{2}{|c|}{ Tipo 1} & \multicolumn{2}{|c|}{ Tipo 2} & \multicolumn{2}{|c|}{ Tipo 3} & \multicolumn{2}{|c|}{ Tipo 4} & \multirow[b]{2}{*}{$x^{2}$} \\
\hline & $\mathrm{N}$ & $\%$ & $\mathrm{~N}$ & $\%$ & $\mathrm{~N}$ & $\%$ & $\mathrm{~N}$ & $\%$ & \\
\hline \multicolumn{10}{|l|}{ Ingresos } \\
\hline mensuales & 6 & 18.8 & 4 & 50 & 21 & 24.1 & 6 & 20 & 17.98 \\
\hline Sin ingresos & 1 & 3.1 & - & - & 1 & 1.1 & 1 & 3.3 & \\
\hline Menos de & 2 & 6.3 & - & - & 14 & 16.1 & 6 & 20 & \\
\hline 30.000 & 7 & 21.9 & 1 & 12.5 & 32 & 36.8 & 9 & 30 & \\
\hline Entre 31 y & 7 & 21.9 & 1 & 12.5 & 10 & 11.5 & 5 & 16.7 & \\
\hline 60 & 9 & $28.1 *$ & 2 & $25 *$ & 9 & 10.3 & 3 & 10 & \\
\hline \multicolumn{10}{|l|}{$\begin{array}{l}\text { Entre } 61 \text { y } \\
90\end{array}$} \\
\hline Entre 91 y & 9 & $24.3 *$ & 2 & 22.2 & 8 & 8.8 & 3 & 8.3 & $39.9 * * * *$ \\
\hline 120 & 6 & $16.2 *$ & 2 & 22.2 & 37 & $40.7 *$ & 9 & 25 & \\
\hline \multirow[t]{2}{*}{ Más de 120} & 8 & 21.6 & 1 & 11.1 & 2 & $2.2^{*}$ & 12 & $33.3 *$ & \\
\hline & 2 & 5.4 & 2 & 22.2 & 13 & 14.3 & 6 & 16.7 & \\
\hline $\begin{array}{l}\text { En qué } \\
\text { trabajas } \\
\text { Hostelería }\end{array}$ & 12 & 32.4 & 2 & 22.2 & 31 & 34.1 & 6 & 16.7 & \\
\hline $\begin{array}{l}\text { Servicio } \\
\text { doméstico }\end{array}$ & & & & & & & & & \\
\hline $\begin{array}{l}\text { Venta } \\
\text { ambulante }\end{array}$ & & & & & & & & & \\
\hline Paro & & & & & & & & & \\
\hline Otros & & & & & & & & & \\
\hline
\end{tabular}


Redes - Revista Hispana para el análisis de redes sociales. Volumen 1\#4

Tabla 2.5. Características de las cadenas migratorias y proyecto migratorio por tipo de red Tipo de red de apoyo

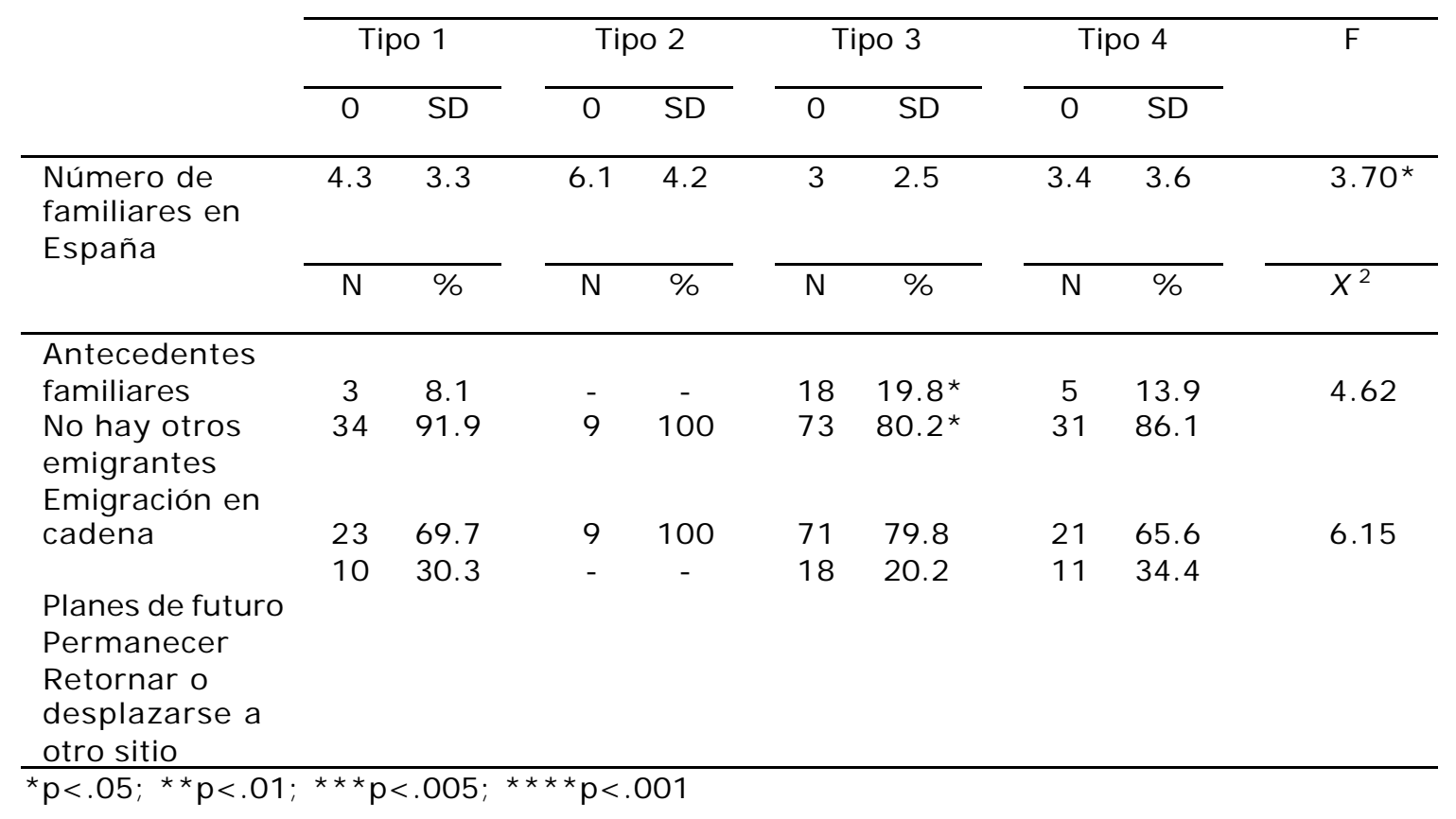


Redes - Revista Hispana para el análisis de redes sociales. Volumen 1\#4

Tabla 2.6. Medias y análisis oneway de la varianza de comportamientos de apoyo y evaluación del apoyo por tipo de red

\begin{tabular}{|c|c|c|c|c|c|c|}
\hline & \multicolumn{6}{|c|}{ Tipo de red de ar } \\
\hline & \multicolumn{2}{|c|}{ Tipo 1} & \multicolumn{2}{|c|}{ Tipo 2} & \multicolumn{2}{|c|}{ Tipo 3} \\
\hline & 0 & SD & 0 & SD & 0 & SL \\
\hline \multicolumn{7}{|l|}{ COMPORTAMIENTOS DE APOYO } \\
\hline Apoyo otorgado & 17.6 & 6 & 18.7 & 5.9 & 16.2 & $6 . \vdots$ \\
\hline Apoyo recibido & 21.3 & 6.2 & 19.5 & 6.4 & 20 & 6.7 \\
\hline Ratio de apoyo otorgado/recibido & .84 & .23 & .95 & .00 & .85 & .31 \\
\hline \multicolumn{7}{|l|}{ VALORACIÓN DEL APOYO } \\
\hline Satisfacción & .94 & .14 & .92 & .00 & .95 & .16 \\
\hline Suficiencia & 26.9 & 6.7 & 26.4 & 6.9 & 25.7 & 8.] \\
\hline
\end{tabular}


Redes - Revista Hispana para el análisis de redes sociales. Volumen 1\#4

Tabla 2.7. Bienestar, número de problemas y utilización de servicios

\begin{tabular}{|c|c|c|c|c|c|c|}
\hline & \multicolumn{6}{|c|}{ Tipo de red de $a r$} \\
\hline & \multicolumn{2}{|c|}{ Tipo 1} & \multicolumn{2}{|c|}{ Tipo 2} & \multicolumn{2}{|c|}{ Tipo 3} \\
\hline & 0 & SD & 0 & SD & 0 & $\overline{\mathrm{SC}}$ \\
\hline Depresión & 14.1 & 8.3 & 17.1 & 4.4 & 20.4 & $\overline{8.5}$ \\
\hline Número de problemas percibidos & 26.9 & 6.5 & 26.3 & 5.7 & 26.4 & $6 . \overline{3}$ \\
\hline Número de servicios que conoce & 4.8 & 2.6 & 4.3 & 2 & 4.4 & $2 . \overline{7}$ \\
\hline \multirow[t]{2}{*}{ Número de servicios utilizados } & 1 & 1.3 & 2 & 1.8 & 1.1 & 1.1 \\
\hline & $\mathrm{N}$ & $\%$ & $\mathrm{~N}$ & $\%$ & $\mathrm{~N}$ & $\%$ \\
\hline \multicolumn{7}{|c|}{ Satisfacción con las circunstancias actuales } \\
\hline Algo & 3 & 8.1 & - & - & 11 & 12. \\
\hline Intermedio & 22 & 59.5 & 4 & 44.4 & 52 & 57. \\
\hline Mucho & 12 & 32.4 & 5 & 55.6 & 28 & 30. \\
\hline
\end{tabular}


Redes - Revista Hispana para el análisis de redes sociales. Volumen 1\#4

Tabla 3.1. Medias y análisis oneway de la varianza de las variables de apoyo por tipo de red

Tipo de red de

\begin{tabular}{|c|c|c|c|c|c|}
\hline \multicolumn{2}{|c|}{ Tipo 1} & \multicolumn{2}{|c|}{ Tipo 2} & \multicolumn{2}{|c|}{ Tipo 3} \\
\hline 0 & SD & 0 & SD & 0 & $\overline{S L}$ \\
\hline 14 & 2.91 & 7 & 2.27 & 5 & 1.9 \\
\hline 4.25 & 1.16 & 2.86 & 0.73 & 5.26 & 1.1 \\
\hline 0.46 & 0.21 & 0.77 & 0.16 & 0.25 & 0.1 \\
\hline
\end{tabular}

Tamaño de la red de apoyo

Multiplicidad

Especificidad

$* * * p<.001$ 
Tabla 3.2. Características socio-demográficas de los inmigrantes por tipo de red

\begin{tabular}{|c|c|c|c|c|c|c|}
\hline & \multicolumn{6}{|c|}{ Tipo de red de ar } \\
\hline & \multicolumn{2}{|c|}{ Tipo 1} & \multicolumn{2}{|c|}{ Tipo 2} & \multicolumn{2}{|c|}{ Tipo 3} \\
\hline & 0 & SD & 0 & SD & 0 & $\overline{\mathrm{SC}}$ \\
\hline Edad & 34.6 & 10.5 & 37.4 & 11.5 & 36.6 & 12. \\
\hline Año de entrada & 85.7 & 5.4 & 87.6 & 6.6 & 90 & 6.5 \\
\hline \multirow[t]{2}{*}{ Años de escolarización } & 9.4 & 3.5 & 10.1 & 3.7 & 9.3 & 3.5 \\
\hline & $\mathrm{N}$ & $\%$ & $\mathrm{~N}$ & $\%$ & $\mathrm{~N}$ & $\%$ \\
\hline \multicolumn{7}{|l|}{ Género } \\
\hline Hombre & 12 & 48 & 18 & $36 *$ & 21 & 40. \\
\hline Mujer & 13 & 52 & 32 & $64 *$ & 31 & 59. \\
\hline \multicolumn{7}{|l|}{ Estado civil } \\
\hline Soltero & 6 & 24 & 12 & 24 & 7 & 13. \\
\hline Casado/Pareja & 17 & 68 & 31 & 62 & 39 & 75 \\
\hline Divorciado/Viudo & 2 & 8 & 7 & 14 & 6 & 11. \\
\hline \multicolumn{7}{|l|}{ Nacionalidad } \\
\hline Marroquí & 10 & 40 & 33 & $66^{*}$ & 31 & 59.6 \\
\hline Senegalesa & 2 & 8 & 2 & $4 *$ & 3 & 5.8 \\
\hline Filipina & 13 & 52 & 15 & 30 & 18 & 34. \\
\hline \multicolumn{7}{|l|}{ Documentación en regla } \\
\hline Permiso de residencia & 5 & $20 *$ & 18 & 36 & 23 & 45. \\
\hline Permiso de trabajo & 9 & 36 & 17 & 34 & 14 & 27. \\
\hline Como turista & - & - & 1 & 2 & - & - \\
\hline Tarjeta de estudiante & - & - & 3 & $6 *$ & 1 & 2 \\
\hline Irregular o en contencioso & 2 & 8 & 3 & 6 & 8 & 15. \\
\hline Permiso comunitario & 9 & $36 *$ & 8 & 16 & 5 & $9 . \varepsilon$ \\
\hline
\end{tabular}


Redes - Revista Hispana para el análisis de redes sociales. Volumen 1\#4

Tabla 3.3. Movilidad geográfica y tipo de vivienda por tipo de red

\begin{tabular}{|c|c|c|c|c|c|c|c|c|c|}
\hline & \multicolumn{9}{|c|}{ Tipo de red de apoyo } \\
\hline & \multicolumn{2}{|c|}{ Tipo 1} & \multicolumn{2}{|c|}{ Tipo 2} & \multicolumn{2}{|c|}{ Tipo 3} & \multicolumn{2}{|c|}{ Tipo 4} & \multirow[b]{2}{*}{$x^{2}$} \\
\hline & $\mathrm{N}$ & $\%$ & $\mathrm{~N}$ & $\%$ & $\mathrm{~N}$ & $\%$ & $\mathrm{~N}$ & $\%$ & \\
\hline $\begin{array}{l}\text { Tipo de vivienda } \\
\text { Alquilada } \\
\text { Propia } \\
\text { Del empresario } \\
\text { Otra }\end{array}$ & $\begin{array}{c}15 \\
7 \\
1 \\
2\end{array}$ & $\begin{array}{c}60 \\
28^{*} \\
4 \\
8\end{array}$ & $\begin{array}{c}35 \\
4 \\
5 \\
6\end{array}$ & $\begin{array}{c}70 \\
8 \\
10 \\
12\end{array}$ & $\begin{array}{c}31 \\
8 \\
9 \\
4\end{array}$ & $\begin{array}{c}59.6 \\
15.4 \\
17.3 \\
7.7\end{array}$ & $\begin{array}{c}38 \\
2 \\
4 \\
2\end{array}$ & $\begin{array}{c}82.6^{*} \\
4.3^{*} \\
8.7 \\
4.3\end{array}$ & 15.86 \\
\hline $\begin{array}{l}\text { Movilidad entre } \\
\text { provincias } \\
\text { No me he movido } \\
\text { Desplazamientos } \\
\text { previos o }\end{array}$ & $\begin{array}{c}18 \\
7\end{array}$ & $\begin{array}{l}72 \\
28\end{array}$ & $\begin{array}{l}37 \\
13\end{array}$ & $\begin{array}{l}74 \\
26\end{array}$ & $\begin{array}{l}38 \\
14\end{array}$ & $\begin{array}{l}73.1 \\
26.9\end{array}$ & $\begin{array}{l}30 \\
16\end{array}$ & $\begin{array}{l}65.2 \\
34.8\end{array}$ & 1.08 \\
\hline $\begin{array}{l}\text { actuales } \\
\text { Frecuencia de } \\
\text { visita al país de } \\
\text { origen } \\
\text { Nunca hasta } \\
\text { ahora } \\
\text { Menos de una } \\
\text { vez al año } \\
\text { Una vez al año } \\
\text { Dos veces al año } \\
\text { Tres veces al año }\end{array}$ & $\begin{array}{l}- \\
13 \\
9 \\
1 \\
2\end{array}$ & $\begin{array}{l}-* \\
52 \\
36 \\
4 \\
8\end{array}$ & $\begin{array}{c}5 \\
20 \\
12 \\
7 \\
5\end{array}$ & $\begin{array}{l}10.2 \\
40.8 \\
24.5 \\
14.3^{*} \\
10.2\end{array}$ & $\begin{array}{c}7 \\
18 \\
17 \\
5 \\
4\end{array}$ & $\begin{array}{c}13.7 \\
35.3 \\
33.3 \\
9.8 \\
7.8\end{array}$ & $\begin{array}{l}10 \\
15 \\
14 \\
1 \\
2\end{array}$ & $\begin{array}{c}23.8 \\
35.7 \\
33.3 \\
2.4 \\
4.8\end{array}$ & 15.06 \\
\hline
\end{tabular}


Redes - Revista Hispana para el análisis de redes sociales. Volumen 1\#4

Tabla 3.4. Situación socioeconómica por tipo de red

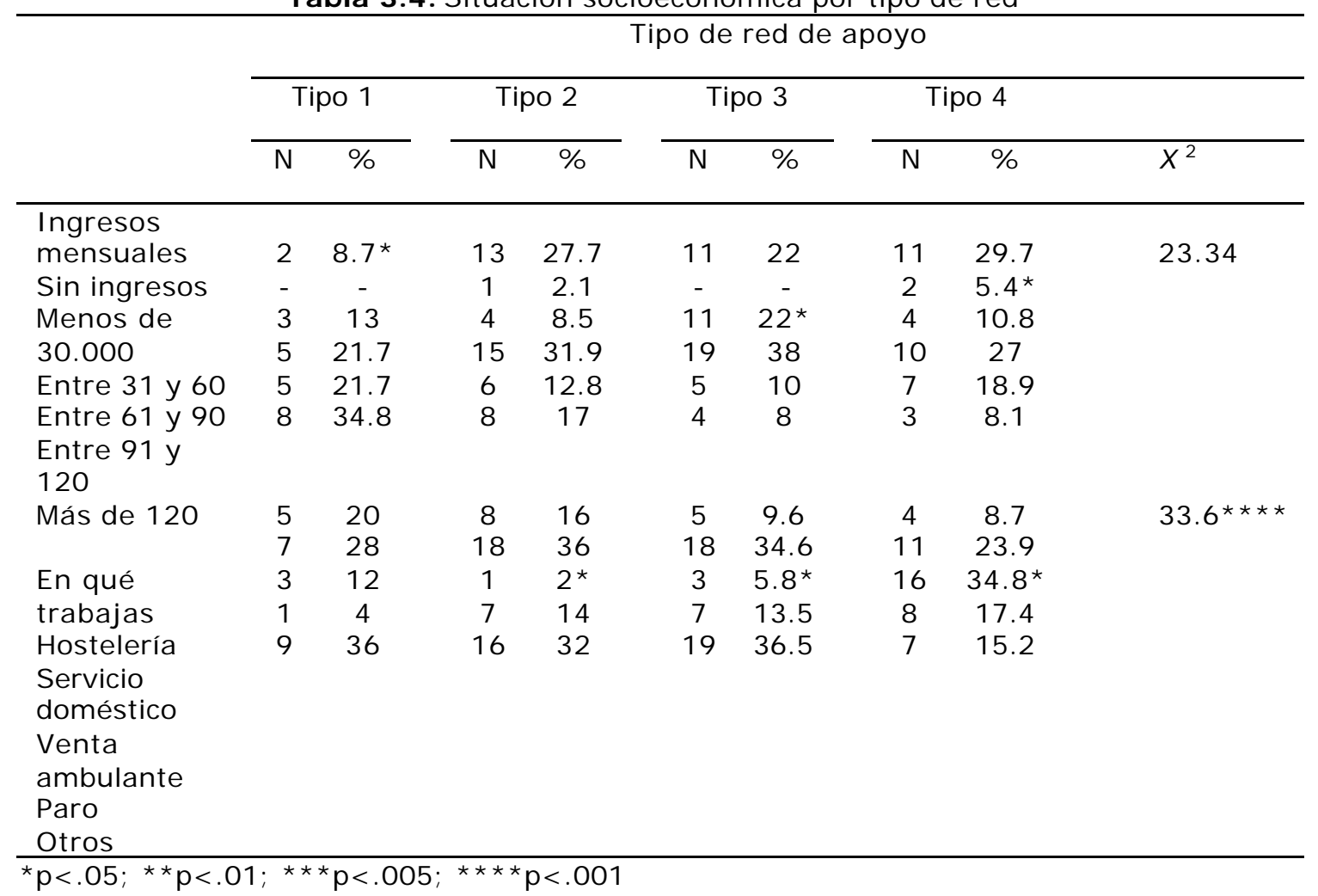


Redes - Revista Hispana para el análisis de redes sociales. Volumen 1\#4

Tabla 3.5. Características de las cadenas migratorias y proyecto migratorio por tipo de red

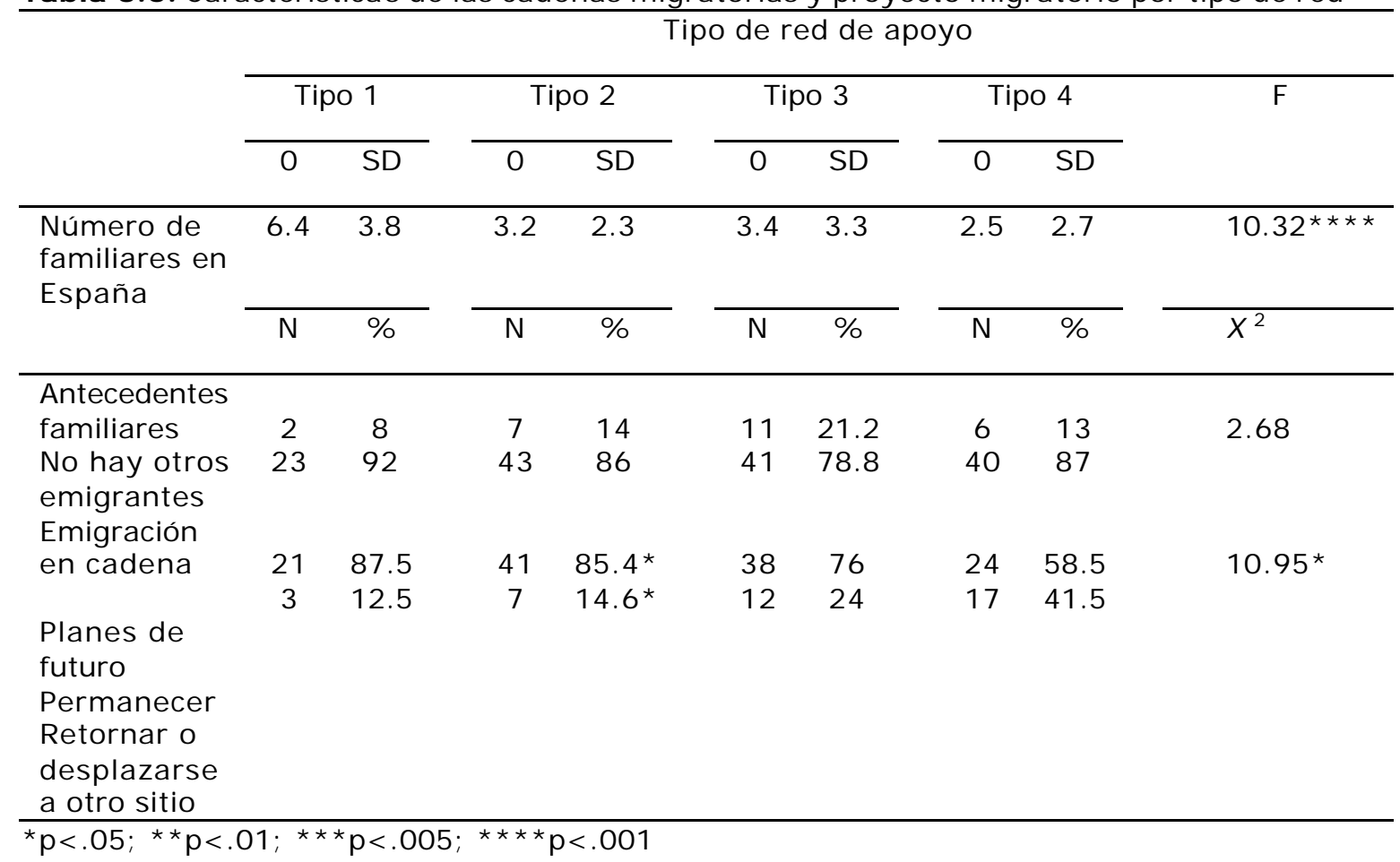


Redes - Revista Hispana para el análisis de redes sociales. Volumen 1\#4

Tabla 3.6. Medias y análisis oneway de la varianza de comportamientos de apoyo y evaluación del apoyo por tipo de red

\begin{tabular}{|c|c|c|c|c|c|c|}
\hline & \multicolumn{6}{|c|}{ Tipo de red de a } \\
\hline & \multicolumn{2}{|c|}{ Tipo 1} & \multicolumn{2}{|c|}{ Tipo 2} & \multicolumn{2}{|c|}{ Tipo 3} \\
\hline & 0 & SD & 0 & SD & 0 & $\overline{\mathrm{SC}}$ \\
\hline \multicolumn{7}{|l|}{ COMPORTAMIENTOS DE APOYO } \\
\hline Apoyo otorgado & 17.8 & 6.2 & 16.3 & 5.7 & 15.9 & 6. \\
\hline Apoyo recibido & 21.9 & 6.4 & 19.7 & 6.5 & 20.3 & 7.1 \\
\hline Ratio de apoyo otorgado/recibido & .84 & .27 & .89 & .32 & .81 & .26 \\
\hline \multicolumn{7}{|l|}{ VALORACIÓN DEL APOYO } \\
\hline Satisfacción & .92 & .00 & .92 & .24 & .97 & $.1 !$ \\
\hline Suficiencia & 27.8 & 4.8 & 25.1 & 7.9 & 26.2 & $7 . \varepsilon$ \\
\hline
\end{tabular}


Redes - Revista Hispana para el análisis de redes sociales. Volumen 1\#4

Tabla 3.7. Bienestar, número de problemas y utilización de servicios

\begin{tabular}{|c|c|c|c|c|c|c|}
\hline & \multicolumn{6}{|c|}{ Tipo de red de a } \\
\hline & \multicolumn{2}{|c|}{ Tipo 1} & \multicolumn{2}{|c|}{ Tipo 2} & \multicolumn{2}{|c|}{ Tipo 3} \\
\hline & 0 & SD & 0 & SD & 0 & $\overline{\mathrm{SC}}$ \\
\hline Depresión & 18.1 & 6.1 & 19.9 & 9.6 & 18.5 & 9. \\
\hline Número de problemas percibidos & 27.2 & 6.5 & 25.1 & 6.6 & 27.6 & 5.4 \\
\hline Número de servicios que conoce & 6.1 & 1.9 & 4.4 & 2.9 & 4 & 2.5 \\
\hline \multirow[t]{2}{*}{ Número de servicios utilizados } & 2 & 1.7 & 1.1 & 1.1 & 1 & 1.4 \\
\hline & $\mathrm{N}$ & $\%$ & $\mathrm{~N}$ & $\%$ & $\mathrm{~N}$ & $\%$ \\
\hline \multicolumn{7}{|c|}{ Satisfacción con las circunstancias actuales } \\
\hline Algo & 1 & 4 & 7 & $14 *$ & 5 & 9.6 \\
\hline Intermedio & 14 & 56 & 29 & 58 & 28 & 53. \\
\hline Mucho & 10 & 40 & 14 & 28 & 19 & 36. \\
\hline
\end{tabular}


Tabla 4.1. Relación de las tipologías según composición y según funciones de apoyo: residuos corregidos del análisis chi-cuadrado

\begin{tabular}{|c|c|c|c|c|c|}
\hline & & \multicolumn{4}{|c|}{ Tipología según funciones de apoyo } \\
\hline & & $\begin{array}{l}\text { Redes con } \\
\text { predominio } \\
\text { de funciones } \\
\text { psicológicas }\end{array}$ & $\begin{array}{l}\text { Redes con } \\
\text { predominio } \\
\text { de funciones } \\
\text { cotidianas }\end{array}$ & $\begin{array}{c}\text { Redes poco } \\
\text { diferenciadas }\end{array}$ & $\begin{array}{c}\text { Redes } \\
\text { funcionalmente } \\
\text { compensadas }\end{array}$ \\
\hline \multirow[t]{4}{*}{$\begin{array}{l}\text { Tipología } \\
\text { según } \\
\text { composición } \\
\text { familiar y } \\
\text { étnica } \\
\end{array}$} & $\begin{array}{c}\text { Redes } \\
\text { étnicas con } \\
\text { predominio } \\
\text { de familiares }\end{array}$ & 0.8 & 4.7 & -3.0 & 0.3 \\
\hline & $\begin{array}{c}\text { Redes } \\
\text { étnicas de } \\
\text { familiares y } \\
\text { amigos }\end{array}$ & 3.1 & -3.1 & 7.2 & -4.1 \\
\hline & $\begin{array}{l}\text { Redes } \\
\text { mixtas con } \\
\text { predominio } \\
\text { de amigos }\end{array}$ & 2.5 & 1.2 & -3.2 & 0.8 \\
\hline & $\begin{array}{l}\text { Redes } \\
\text { étnicas con } \\
\text { predominio } \\
\text { de amigos }\end{array}$ & 1.2 & -0.5 & -3.8 & 3.7 \\
\hline
\end{tabular}


Redes - Revista Hispana para el análisis de redes sociales. Volumen 1\#4

Tabla 4.2. Relación de las tipologías según composición y según estructura: residuos corregidos del análisis chi-cuadrado

\begin{tabular}{|c|c|c|c|c|c|}
\hline & & \multicolumn{4}{|c|}{ Tipología según composición familiar y étnica } \\
\hline & & $\begin{array}{l}\text { Redes étnicas } \\
\text { con } \\
\text { predominio } \\
\text { de familiares }\end{array}$ & $\begin{array}{c}\text { Redes } \\
\text { étnicas de } \\
\text { familiares y } \\
\text { amigos }\end{array}$ & $\begin{array}{c}\text { Redes mixtas } \\
\text { con } \\
\text { predominio } \\
\text { de amigos }\end{array}$ & $\begin{array}{c}\text { Redes étnicas } \\
\text { con } \\
\text { predominio } \\
\text { de amigos }\end{array}$ \\
\hline \multirow{4}{*}{$\begin{array}{l}\text { Tipología } \\
\text { según } \\
\text { estructura } \\
\text { de la red } \\
\end{array}$} & Redes amplias & 6.2 & -5.4 & 5.2 & -5.7 \\
\hline & $\begin{array}{c}\text { Redes } \\
\text { intermedias de } \\
\text { vínculos } \\
\text { especializados }\end{array}$ & -1.1 & 2.1 & -1.8 & -0.4 \\
\hline & $\begin{array}{c}\text { Redes pequeñas } \\
\text { polivalentes }\end{array}$ & -2.8 & 4.7 & -2.4 & -1.7 \\
\hline & $\begin{array}{c}\text { Redes } \\
\text { intermedias } \\
\text { polivalentes }\end{array}$ & -0.9 & -2.7 & 0.1 & 3.4 \\
\hline
\end{tabular}


Redes - Revista Hispana para el análisis de redes sociales. Volumen 1\#4

Tabla 4.3. Relación de las tipologías según funciones de apoyo y según estructura: residuos corregidos del análisis chi-cuadrado

\begin{tabular}{|c|c|c|c|c|c|}
\hline & \multicolumn{4}{|c|}{ Tipología según funciones de apoyo } \\
\hline & & $\begin{array}{l}\text { Redes con } \\
\text { predominio } \\
\text { de funciones } \\
\text { psicológicas }\end{array}$ & $\begin{array}{c}\text { Redes con } \\
\text { predominio } \\
\text { de funciones } \\
\text { cotidianas }\end{array}$ & $\begin{array}{l}\text { Redes poco } \\
\text { diferenciadas }\end{array}$ & $\begin{array}{c}\text { Redes } \\
\text { funcionalmente } \\
\text { compensadas }\end{array}$ \\
\hline \multirow{4}{*}{$\begin{array}{l}\text { Tipología } \\
\text { según } \\
\text { estructura } \\
\text { de la red }\end{array}$} & $\begin{array}{c}\text { Redes amplias } \\
\text { equilibradas }\end{array}$ & 2.5 & 3.6 & -4.4 & 1.0 \\
\hline & $\begin{array}{c}\text { Redes } \\
\text { intermedias de } \\
\text { vínculos } \\
\text { especializados }\end{array}$ & -3.1 & -2.0 & 7 & -4.3 \\
\hline & $\begin{array}{c}\text { Redes } \\
\text { pequeñas } \\
\text { polivalentes }\end{array}$ & 0.4 & -2.0 & 2.9 & -2.8 \\
\hline & $\begin{array}{c}\text { Redes } \\
\text { intermedias } \\
\text { polivalentes }\end{array}$ & 0.9 & 1.2 & -6.6 & 6.5 \\
\hline
\end{tabular}


Redes - Revista Hispana para el análisis de redes sociales. Volumen 1\#4

Tabla 4.4. Análisis factorial de componentes principales con rotación varimax de las variables criterio

Matriz de componentes rotados

\begin{tabular}{|c|c|c|c|}
\hline & Factor 1 & Factor 2 & Factor 3 \\
\hline $\begin{array}{l}\text { 1. № de compatriotas } \\
\text { 2. № de españoles } \\
\text { 3. № de familiares } \\
\text { 4. № de no-familiares } \\
\text { 5. Apoyo psicológico cotidiano } \\
\text { 6. Apoyo instrumental cotidiano } \\
\text { 7. Apoyo instrumental de crisis } \\
\text { 8. Apoyo psicológico de crisis } \\
\text { 9. Proporción de vínculos } \\
\text { especializados } \\
\text { 10. Multiplicidad media de los } \\
\text { vínculos } \\
\text { 11. Tamaño de la red de apoyo }\end{array}$ & $\begin{array}{l}, 218 \\
-, 144 \\
-, 125 \\
, 221 \\
, \mathbf{5 6 4} \\
, 702 \\
, 753 \\
, 123 \\
-, \mathbf{8 6 6} \\
, 908 \\
, 123\end{array}$ & $\begin{array}{c}\mathbf{8 9 2} \\
3,857 \mathrm{E}-03 \\
\mathbf{8 9 4} \\
, 129 \\
, 541 \\
\mathbf{7 6 6} \\
, 247 \\
, 249 \\
, 156 \\
-, 230 \\
\mathbf{, 7 6 6}\end{array}$ & $\begin{array}{c}, 138 \\
, \mathbf{8 2 8} \\
-9,014 \mathrm{E}-02 \\
, \mathbf{8 5 0} \\
, 331 \\
4,821 \mathrm{E}-02 \\
, 242 \\
, \mathbf{2 5 4} \\
, 146 \\
-, 173 \\
, 614\end{array}$ \\
\hline
\end{tabular}


Redes - Revista Hispana para el análisis de redes sociales. Volumen 1\#4

Tabla 4.5. Matriz de correlaciones de las variables-criterio

\begin{tabular}{|c|c|c|c|c|c|c|c|c|c|c|}
\hline $\begin{array}{c}\text { Variables de } \\
\text { la red de } \\
\text { apoyo }\end{array}$ & 1 & 2 & 3 & 4 & 5 & 6 & 7 & 8 & 9 & 10 \\
\hline $\begin{array}{l}\text { 1. No de } \\
\text { compatriotas } \\
\text { 2. No de } \\
\text { españoles } \\
\text { 3. No de } \\
\text { familiares } \\
\text { 4. No de no- } \\
\text { familiares } \\
\text { 5. Apoyo } \\
\text { psicológico } \\
\text { cotidiano } \\
\text { 6. Apoyo } \\
\text { instrumental } \\
\text { cotidiano } \\
\text { 7. Apoyo } \\
\text { instrumental } \\
\text { de crisis } \\
\text { 8. Apoyo } \\
\text { psicológico de } \\
\text { crisis } \\
\text { 9. Proporción } \\
\text { de vínculos } \\
\text { especializados } \\
\text { 10. } \\
\text { Multiplicidad } \\
\text { media de los } \\
\text { vínculos } \\
\text { 11. Tamaño } \\
\text { de la red de } \\
\text { apoyo }\end{array}$ & $\begin{array}{c}- \\
-.061 \\
.640 * * \\
.399 * * \\
.634 * * \\
.452 * * \\
.397 * * \\
.418 * * \\
-.015 \\
-.037 \\
- \\
.803 * *\end{array}$ & $\begin{array}{c}- \\
- \\
.131 \\
.442 * * \\
.175^{*} \\
-.021 \\
.128 \\
.122 \\
.192 * \\
- \\
.227 * * \\
.490^{*} *\end{array}$ & $\begin{array}{c}- \\
- \\
- \\
-.116 \\
.344 * * \\
.224^{*} * \\
.144 \\
.145 \\
.175^{*} \\
- \\
.260^{*} * \\
.614^{*} *\end{array}$ & $\begin{array}{c}- \\
- \\
- \\
- \\
.479 * * \\
.238 * * \\
.340 * * \\
.375 * * \\
-.040 \\
-.009 \\
.652 * *\end{array}$ & $\begin{array}{c}- \\
- \\
- \\
- \\
- \\
.570 * * \\
.510 * * \\
.523 * * \\
- \\
.419 * * \\
.350 * * \\
.686 * *\end{array}$ & $\begin{array}{c}- \\
- \\
- \\
- \\
- \\
- \\
.601 * * \\
.593^{* *} \\
- \\
.469 * * \\
.471 * * \\
.392 * *\end{array}$ & $\begin{array}{c}- \\
- \\
- \\
- \\
- \\
- \\
- \\
.671 * * \\
- \\
.472 * * \\
.594 * * \\
.418^{*} *\end{array}$ & $\begin{array}{c}- \\
- \\
- \\
- \\
- \\
- \\
- \\
- \\
- \\
.531 * * \\
.577^{*} * \\
.428 * *\end{array}$ & $\begin{array}{c}- \\
- \\
- \\
- \\
- \\
- \\
- \\
- \\
- \\
- \\
.824 * * \\
.073\end{array}$ & $\begin{array}{c}- \\
- \\
- \\
- \\
- \\
- \\
- \\
- \\
- \\
- \\
- \\
.163 *\end{array}$ \\
\hline
\end{tabular}


Redes - Revista Hispana para el análisis de redes sociales. Volumen 1\#4

Tabla 5.1. Medias y análisis oneway de la varianza de las variables de apoyo por tipo de red

\begin{tabular}{|c|c|c|c|c|c|c|c|c|c|c|c|}
\hline & \multicolumn{11}{|c|}{ Tipo de red de apoyo } \\
\hline & \multicolumn{2}{|c|}{ Tipo 1} & \multicolumn{2}{|c|}{ Tipo 2} & \multicolumn{2}{|c|}{ Tipo 3} & \multicolumn{2}{|c|}{ Tipo 4} & \multicolumn{2}{|c|}{ Tipo 5} & \multirow[t]{2}{*}{$\mathrm{F}$} \\
\hline & 0 & SD & 0 & SD & 0 & SD & 0 & SD & 0 & SD & \\
\hline $\begin{array}{l}\text { Apoyo } \\
\text { cotidiano } \\
\text { psicológico } \\
\text { Apoyo } \\
\text { instrumental } \\
\text { de crisis } \\
\text { Compatriotas } \\
\text { en la red } \\
\text { personal } \\
\text { Españoles en } \\
\text { la red } \\
\text { personal } \\
\text { Familiares en } \\
\text { la red } \\
\text { personal } \\
\text { No-familiares } \\
\text { en la red } \\
\text { personal } \\
\text { Multiplicidad } \\
\text { media de los } \\
\text { vínculos }\end{array}$ & $\begin{array}{l}4.62 \\
1.83 \\
7.54 \\
1.31 \\
3.49 \\
7.54 \\
3.87\end{array}$ & $\begin{array}{l}2.37 \\
0.94 \\
2.15 \\
1.52 \\
1.76 \\
3.77 \\
1.58\end{array}$ & $\begin{array}{c}6.97 \\
3.78 \\
4.5 \\
8.37 \\
4 \\
10.5 \\
5.03\end{array}$ & $\begin{array}{l}1.64 \\
1.67 \\
3.29 \\
2.92 \\
2.78 \\
3.5 \\
1.77\end{array}$ & $\begin{array}{l}2.11 \\
1.24 \\
3.93 \\
0.69 \\
2.51 \\
2.74 \\
4.42\end{array}$ & $\begin{array}{l}1.26 \\
0.73 \\
1.59 \\
1.11 \\
1.80 \\
1.97 \\
1.83\end{array}$ & $\begin{array}{l}8.5 \\
4.34 \\
12.6 \\
1.07 \\
8.92 \\
6.21 \\
5.47\end{array}$ & $\begin{array}{l}3.37 \\
2.89 \\
2.68 \\
1.21 \\
2.53 \\
4.85 \\
1.56\end{array}$ & $\begin{array}{c}5.58 \\
4.34 \\
6.03 \\
0.29 \\
1.4 \\
5.94 \\
9.51\end{array}$ & $\begin{array}{l}2.16 \\
1.57 \\
2.23 \\
0.93 \\
1.5 \\
3.76 \\
2.68\end{array}$ & $\begin{array}{c}46.34 * * \\
46.19^{* *} \\
62.7^{*} * * \\
66.61^{* *} \\
44.67^{* *} \\
22.98^{* *} \\
66.21^{* *}\end{array}$ \\
\hline
\end{tabular}


Redes - Revista Hispana para el análisis de redes sociales. Volumen 1\#4

Tabla 5.2. Características socio-demográficas de los inmigrantes por tipo de red

\begin{tabular}{|c|c|c|c|c|c|c|c|}
\hline & & & & & \multicolumn{3}{|c|}{ Tipo de red de apoyo } \\
\hline & \multicolumn{2}{|c|}{ Tipo 1} & \multicolumn{2}{|c|}{ Tipo 2} & \multicolumn{2}{|c|}{ Tipo 3} & \multirow{2}{*}{$\begin{array}{ll} & T \\
& \\
\end{array}$} \\
\hline & 0 & SD & 0 & SD & 0 & SD & \\
\hline Edad & 40.51 & 9.73 & 23 & 4.87 & 36.3 & 12.53 & 34.7 \\
\hline Año de entrada & 86.79 & 6.54 & 87.6 & 5.96 & 89.6 & 6.36 & 85.9 \\
\hline \multirow[t]{2}{*}{ Años de escolarización } & 9.53 & 3.79 & 9.38 & 4.1 & 9.46 & 3.49 & 10.5 \\
\hline & $\mathrm{N}$ & $\%$ & $\mathrm{~N}$ & $\%$ & $\mathrm{~N}$ & $\%$ & $\mathrm{~N}$ \\
\hline \multicolumn{8}{|l|}{ Género } \\
\hline Hombre & 17 & 43.6 & 8 & $100 *$ & 30 & $39 *$ & 5 \\
\hline Mujer & 22 & 56.4 & - & $-*$ & 47 & $61 *$ & 9 \\
\hline \multicolumn{8}{|l|}{ Estado civil } \\
\hline Soltero & 4 & $13.3 *$ & 6 & $75 *$ & 17 & 22.1 & 3 \\
\hline Casado/Pareja & 31 & 79.5 & 2 & $25 *$ & 49 & 63.6 & 11 \\
\hline Divorciado/Viudo & 4 & 10.3 & - & - & 11 & $14.3^{*}$ & - \\
\hline \multicolumn{8}{|l|}{ Nacionalidad } \\
\hline Marroquí & 17 & 43.6 & 6 & 75 & 50 & $64.9 *$ & 5 \\
\hline Senegalesa & 4 & 10.3 & 1 & 12.5 & 4 & $5.2 *$ & - \\
\hline Filipina & 18 & 46.2 & 1 & 12.5 & 23 & 29.9* & 9 \\
\hline \multicolumn{8}{|l|}{ Documentación en regla } \\
\hline Permiso de residencia & 11 & 28.2 & 5 & 62.5 & 33 & 43.4 & 2 \\
\hline Permiso de trabajo & 17 & 43.6 & 2 & 25 & 21 & $27.6 *$ & 4 \\
\hline Como turista & - & - & - & - & 1 & 1.3 & - \\
\hline Tarjeta de estudiante & - & - & - & - & 4 & $5.3 *$ & - \\
\hline Irregular / contencioso & 3 & 7.7 & 1 & 12.5 & 8 & 10.5 & 2 \\
\hline Permiso comunitario & 8 & 20.5 & - & - & 9 & 11.8 & 5 \\
\hline
\end{tabular}


Redes - Revista Hispana para el análisis de redes sociales. Volumen 1\#4

Tabla 5.3. Movilidad geográfica y tipo de vivienda por tipo de red

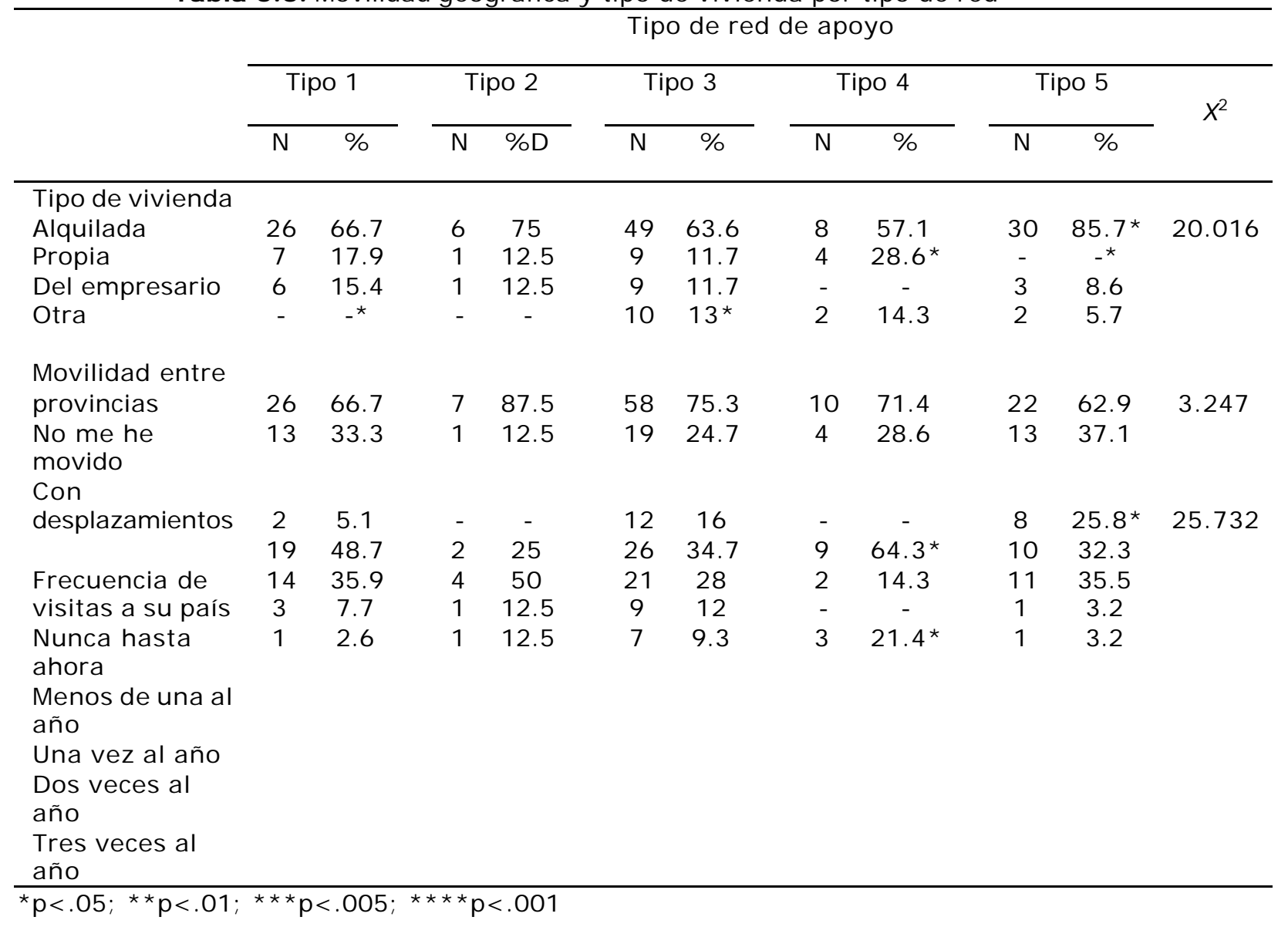


Redes - Revista Hispana para el análisis de redes sociales. Volumen 1\#4

Tabla 5.4. Situación socioeconómica por tipo de red

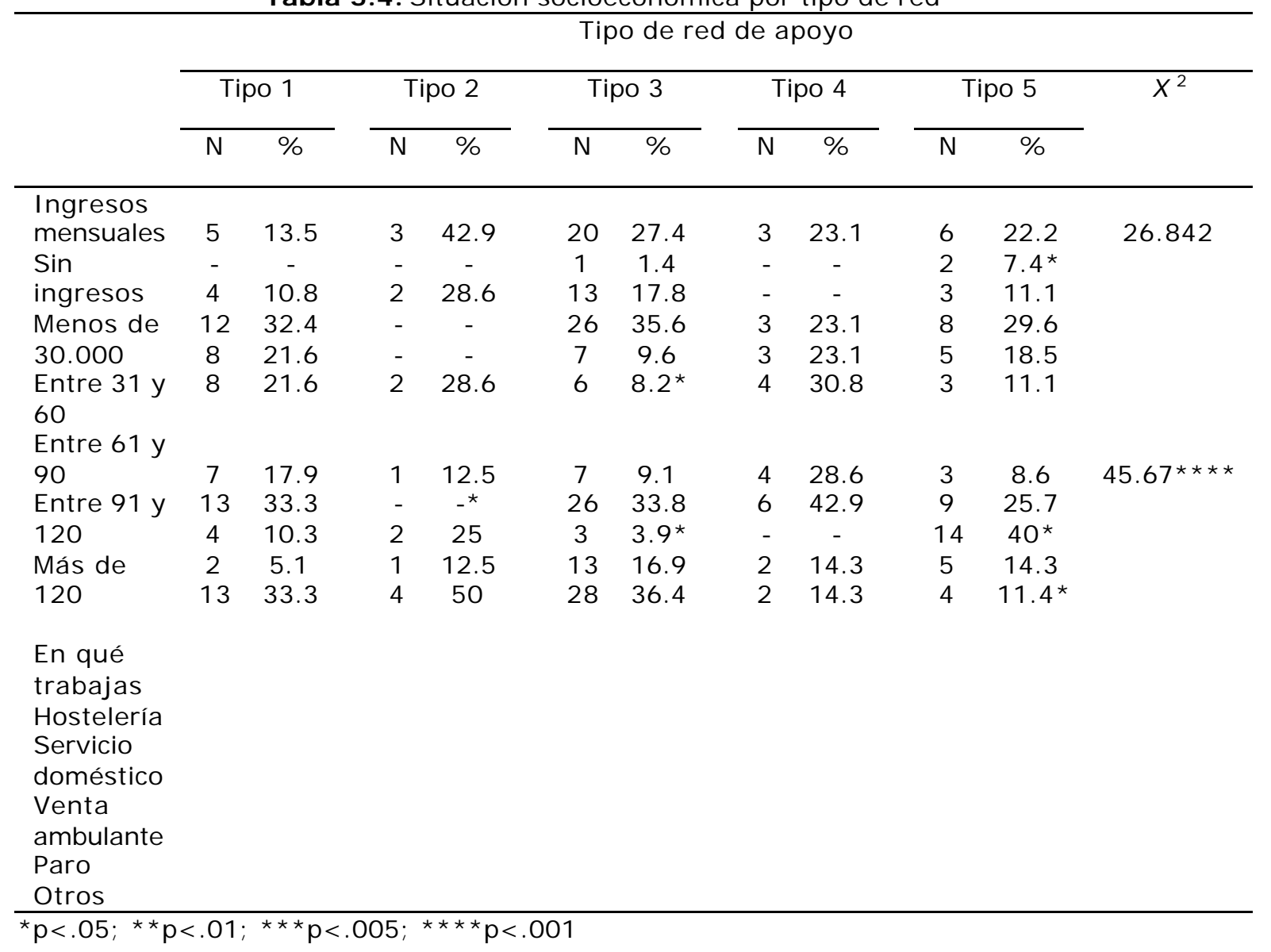


Redes - Revista Hispana para el análisis de redes sociales. Volumen 1\#4

Tabla 5.5. Características de las cadenas migratorias y proyecto migratorio por tipo de red Tipo de red de apoyo

\begin{tabular}{|c|c|c|c|c|c|}
\hline Tipo 1 & Tipo 2 & Tipo 3 & Tipo 4 & Tipo 5 & $\mathrm{~F}$ \\
\hline $0 \quad s$ & $0 \quad S D$ & SD & SD & SD & \\
\hline
\end{tabular}

\begin{tabular}{|c|c|c|c|c|c|c|c|c|c|c|c|}
\hline \multirow{2}{*}{$\begin{array}{l}\text { Número de } \\
\text { familiares en } \\
\text { España }\end{array}$} & 3.25 & 2.32 & 8 & 3.02 & 3.14 & 2.9 & 7.93 & 2.46 & 1.97 & 2.37 & $18.89 * * *$ \\
\hline & $\mathrm{N}$ & $\%$ & $\mathrm{~N}$ & $\%$ & $\mathrm{~N}$ & $\%$ & $\mathrm{~N}$ & $\%$ & $\mathrm{~N}$ & $\%$ & $x^{2}$ \\
\hline $\begin{array}{l}\text { Antecedentes } \\
\text { familiares }\end{array}$ & 7 & 17.9 & - & - & 15 & 19.5 & - & - & 4 & 11.4 & 5.7 \\
\hline $\begin{array}{l}\text { No hay otros } \\
\text { emigrantes } \\
\text { Emigración }\end{array}$ & 32 & 82.1 & 8 & 100 & 62 & 80.5 & 14 & 100 & 31 & 88.6 & \\
\hline en cadena & $\begin{array}{c}29 \\
8\end{array}$ & $\begin{array}{l}78.4 \\
21.6\end{array}$ & $\begin{array}{l}7 \\
1\end{array}$ & $\begin{array}{l}87.5 \\
12.5\end{array}$ & $\begin{array}{l}58 \\
16\end{array}$ & $\begin{array}{l}78.4 \\
21.6\end{array}$ & $\begin{array}{c}14 \\
-\end{array}$ & $\begin{array}{c}100 * \\
-*\end{array}$ & $\begin{array}{l}16 \\
14\end{array}$ & $\begin{array}{l}53.3^{*} \\
46.7^{*}\end{array}$ & $13.824 * *$ \\
\hline $\begin{array}{l}\text { Planes de } \\
\text { futuro } \\
\text { Permanecer } \\
\text { Retornar o ir } \\
\text { a otro sitio }\end{array}$ & & & & & & & & & & & \\
\hline
\end{tabular}


Redes - Revista Hispana para el análisis de redes sociales. Volumen 1\#4

Tabla 5.6. Medias y análisis oneway de la varianza de comportamientos de apoyo y evaluación del apoyo por tipo de red

\begin{tabular}{|c|c|c|c|c|c|c|c|c|c|c|}
\hline & \multicolumn{10}{|c|}{ Tipo de red de apoyo } \\
\hline & \multicolumn{2}{|c|}{ Tipo 1} & \multicolumn{2}{|c|}{ Tipo 2} & \multicolumn{2}{|c|}{ Tipo 3} & \multicolumn{2}{|c|}{ Tipo 4} & \multicolumn{2}{|c|}{ Tipo 5} \\
\hline & 0 & SD & 0 & SD & 0 & SD & 0 & SD & 0 & SD \\
\hline \multicolumn{11}{|l|}{ COMPORTAMIENTOS } \\
\hline DE APOYO & 17.08 & 6.07 & 24.3 & 5.63 & 15.7 & 6.1 & 18.4 & 4.78 & 17.9 & 6.67 \\
\hline Apoyo otorgado & 22.02 & 5.8 & 26.7 & 6.75 & 19.3 & 6.91 & 21.5 & 6.26 & 18.6 & 6.37 \\
\hline Apoyo recibido & 0.79 & 0.23 & 0.93 & 0.22 & 0.86 & 0.32 & 0.89 & 0.22 & 0.98 & 0.26 \\
\hline \multicolumn{11}{|l|}{$\begin{array}{l}\text { Ratio } \\
\text { otorgado/recibido }\end{array}$} \\
\hline & 0.94 & 0.21 & 0.95 & 0.00 & 0.95 & 0.18 & 0.91 & 0.00 & 0.97 & 0.12 \\
\hline VALORACIÓN DEL & 27.42 & 5.99 & 29.7 & 3.54 & 24.8 & 8.44 & 28.1 & 6.05 & 27.4 & 8.82 \\
\hline APOYO & & & & & & & & & & \\
\hline Satisfacción & & & & & & & & & & \\
\hline Suficiencia & & & & & & & & & & \\
\hline
\end{tabular}


Redes - Revista Hispana para el análisis de redes sociales. Volumen 1\#4

Tabla 5.7. Bienestar, número de problemas y utilización de servicios

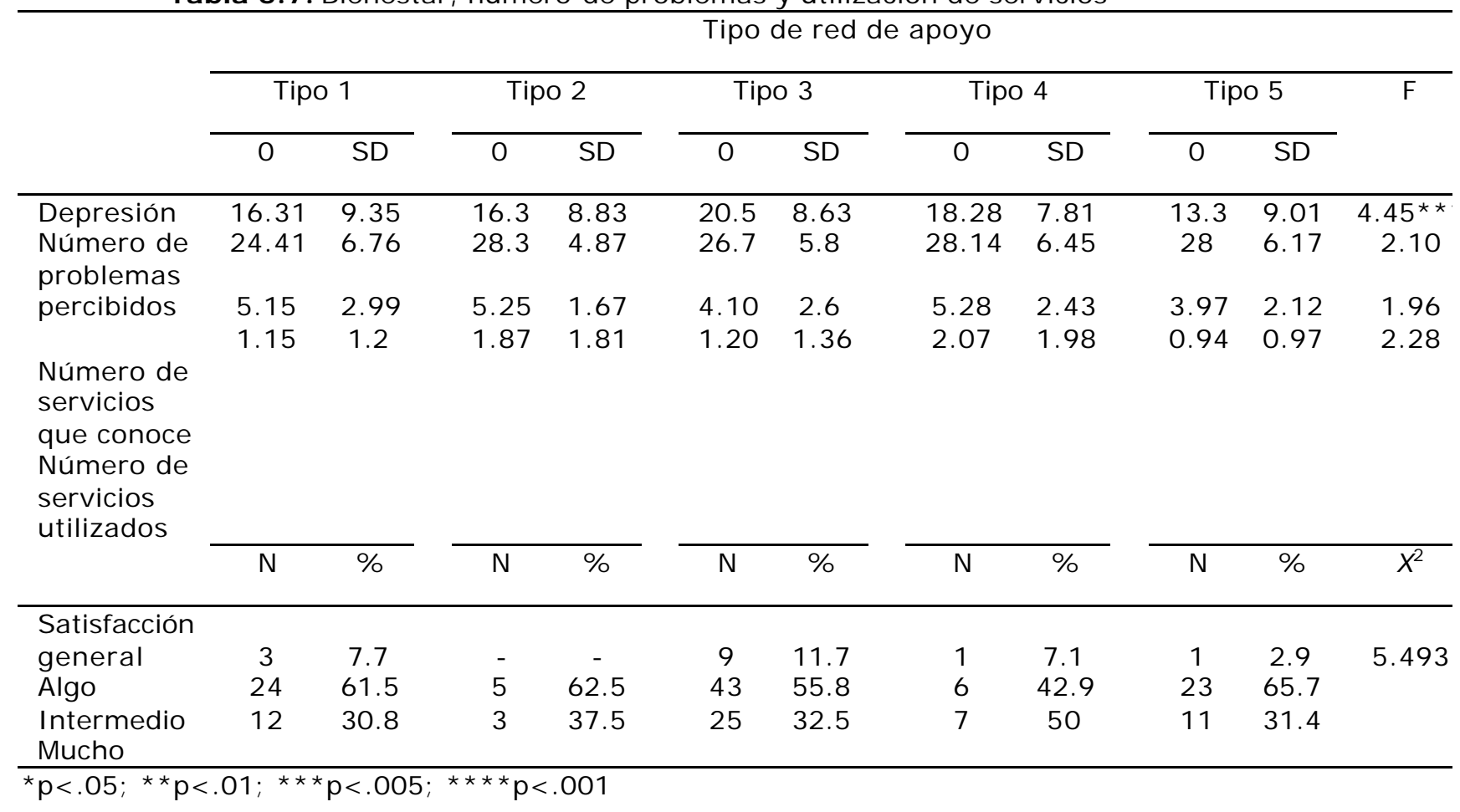

